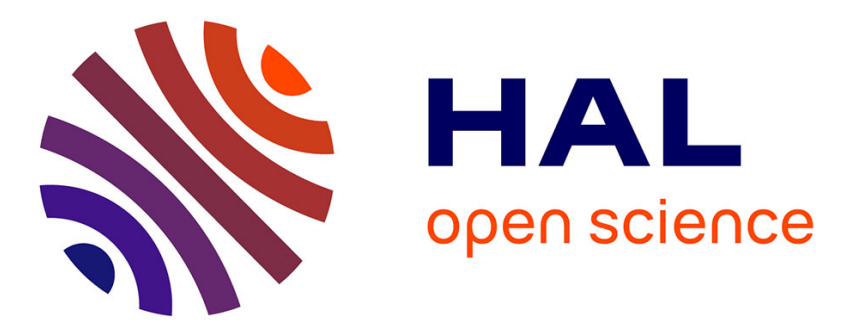

\title{
Effect of glucose-induced Maillard reaction on physical, structural and antioxidant properties of chitosan derivatives-based films
}

Sawsan Affes, Rim Nasri, S.M. Li, Thierry Thami, Arie van Der Lee, Moncef Nasri, Hana Maalej

\section{To cite this version:}

Sawsan Affes, Rim Nasri, S.M. Li, Thierry Thami, Arie van Der Lee, et al.. Effect of glucose-induced Maillard reaction on physical, structural and antioxidant properties of chitosan derivatives-based films. Carbohydrate Polymers, 2021, 255, pp.117341. 10.1016/j.carbpol.2020.117341 . hal-03359461

\section{HAL Id: hal-03359461 \\ https://hal.umontpellier.fr/hal-03359461}

Submitted on 30 Sep 2021

HAL is a multi-disciplinary open access archive for the deposit and dissemination of scientific research documents, whether they are published or not. The documents may come from teaching and research institutions in France or abroad, or from public or private research centers.
L'archive ouverte pluridisciplinaire HAL, est destinée au dépôt et à la diffusion de documents scientifiques de niveau recherche, publiés ou non, émanant des établissements d'enseignement et de recherche français ou étrangers, des laboratoires publics ou privés. 


\section{Highlights}

- Films with varying Mw chitosan and CDP were prepared and heat-treated;

- Functional and structural properties of films were modified by thermal treatment;

- Antioxidant activities of the films were improved due to MR products development. 
4 5

6

7

8

9 5

\section{Effect of glucose-induced Maillard reaction on physical, structural and antioxidant} properties of chitosan derivatives-based films

(3)

Sawsan Affes ${ }^{1}$, Rim Nasri ${ }^{1}$, Suming $\mathrm{Li}^{2}$, Thierry Thami ${ }^{2}$, Arie van der Lee ${ }^{2}$, Moncef Nasri ${ }^{1}$

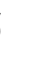
and Hana Maalej ${ }^{1,3 *}$ (6)

${ }^{1}$ Laboratory of Enzyme Engineering and Microbiology, National School of Engineering of Sfax (ENIS), University of Sfax, P.O. Box 1173, Sfax 3038, Tunisia.

${ }^{2}$ European Institute of Membranes, UMR CNRS, 5635, University of Montpellier, Place Eugene Bataillon, 34095 Montpellier Cedex 5, France.

${ }^{3}$ Department of Life Sciences, Faculty of Science of Gabes, Omar Ibn Khattab Street, Gabes 6029, Tunisia.

(3)
4

$6 \quad{ }^{*}$ Corresponding author: Hana Maalej

Address: B.P.68, 3021 Sfax, Tunisia

Tel: +216-20-234699; fax: +216-74-275-595.

9 E-mail address: hannou25@yahoo.fr 


\section{(}

\section{Abstract}

This work focused on studying the physicochemical and antioxidant properties changes of varying molecular weight $(\mathrm{Mw})$ chitosan-depolymerization products (CDP)-based films occurring after crosslinking by heat-treatment and Maillard reaction (MR). Based on color properties and browning index, an enhancement of films properties was observed after treatment at $90{ }^{\circ} \mathrm{C}$ with a reduction in their water content, solubility and contact angle. Brown MR products were developed in heated films containing glucose thus improving their barrier properties. This effect was more pronounced in lower Mw-CDP based films. In addition, according to TGA, EAB and TS analyses an improvement in heat-treated films thermal stability and mechanical properties was detected and further confirmed through FTIR, X-ray and SEM analyses. The evaluation of the antioxidant potential through four different assays allowed to conclude that glucose addition, thermal treatment and the use of low Mw-CDP highly enhanced the MR-modified films antioxidant capacity. Consequently, MR crosslinked chitosan-based films could be potentially used as an alternative for bioactive and functional packaging effective in food oxidation inhibition, especially using low Mw chitosan derivatives.

Keywords: Chitosan-depolymerization products, Molecular weight, Films, Maillard reaction, Physicochemical characterization, Antioxidant potential. 


\section{Introduction}

Increasing environmental concerns led to a growing interest on research and development of biodegradable films based on renewable resources as alternative to synthetic packaging traditionally used in biomedical and food industries (Fernández-de Castro et al., 2016; Ruban et al., 2009). For this purpose, biopolymers, including proteins and polysaccharides are increasingly being used to prepare composite films and coating (Etxabide, Urdanpilleta, Gómez-Arriaran, de la Caba, \& Guerrero, 2017; Kchaou, Benbettaieb, Jridi, Nasri, \& Debeaufort, 2019). Among the most studied biopolymers, chitosan, a natural polysaccharide derived from chitin and composed of D-glucosamine and $\mathrm{N}$-acetylglucosamine units, deserves special attention due its biological properties, such as biocompatibility, non-toxicity, biodegradability and good film-forming ability (Affes et al., 2020a; Hajji, Younes, Affes, Boufi, \& Nasri, 2018). Such characteristics of chitosan depended on its acetylation degree, distribution of acetyl groups, viscosity and especially its molecular weight (Mw). Chitosan derivatives with attractive characteristics, such as low Mw, reduced viscosity and improved antioxidant and antimicrobial potentials, were produced through depolymerization of chitosan by physical, chemical or enzymatic hydrolysis methods (Affes et al., 2019; Aljbour, Beg, \& Gimbun, 2019; Sun et al., 2017).

Some studies have been made to characterize chitosan or chitosan depolymerization products (CDP)-based films as alternative to protect food from drying and oxidation (Fernández-de Castro et al., 2016). In this context, chitosan or CDP-based films properties, such as water resistance, can be improved by enzymatic, chemical and physical modifications to extend their application fields (Leceta, Guerrero, Ibarburu, Dueñas, \& de la Caba, 2013b).

70 There are not many reports concerning non-enzymatic cross-linking methods of chitosan films. As two kinds of different cross-linking browning methods, caramelisation is caused by direct heating of carbohydrate, while Maillard reaction (MR) refers to the condensation 
reactions between nitrogen-containing compounds and carbonyl group of reducing sugars $(\mathrm{Li}$, Lin, \& Chen, 2014). Subsequently, heat treatment is a physical method that had a noticeable effect on improvement of film properties, especially water solubility, thermal stability and mechanical and barrier properties (Fernández-de Castro et al., 2016; Leceta et al., 2013b; Rivero, Garía, \& Pinotti, 2012). Whereas, crosslinking through MR is a chemical process involving three stages in which the initial products are called shift bases that form Amadori products via rearrangement, which undergo further reactions to form irreversible advanced glycation end products (Etxabide et al., 2017; Sun et al., 2017). This method generates fluorescent, brown MR products able to improve chemical, sensory, antioxidant and antimicrobial activities of chitosan films. To control the extension of MR, in order to obtain the properties required for a specific application, various factor should be analyzed, including temperature, time, $\mathrm{pH}$, water activity and concentration, type and ratio of used carbonyl group compounds and reducing sugar (Gullón et al., 2016).

The purpose of this work was to study changes undergone, by crosslinking and Maillard reaction development, in varying $\mathrm{Mw}$ chitosan or CDP-based films by monitoring their physical, functional and microstructural properties before and after heat-treatment at $90{ }^{\circ} \mathrm{C}$ and with and without glucose addition.

\section{Materials and methods}

\subsection{Materials}

Chitosan (Ch) was prepared from shrimp shells chitin and hydrolyzed using the chitosanolytic preparation from Bacillus licheniformis strain as described in our previous study (Affes et al., 2020b). After incubation of the chitosan solution at $50{ }^{\circ} \mathrm{C}$ in the presence of the chitosanolytic preparation, samples were withdrawn at 1 and $24 \mathrm{~h}$, heated at $100{ }^{\circ} \mathrm{C}$ for $10 \mathrm{~min}$, neutralized to $\mathrm{pH} 8.0$ and centrifuged for $30 \mathrm{~min}$ at $8,000 \mathrm{x}$ g. The insoluble part at 1 and $24 \mathrm{~h}$ were freeze-dried and referred as chitosan depolymerization products (CDP) C1 and C24, 
respectively. The average molecular weight $(\mathrm{Mw})$, the intrinsic viscosity, the acetylation degree and the crystallinity index of $\mathrm{Ch}, \mathrm{C} 1$ and $\mathrm{C} 24$ were determined by SEC-HPLC, a semiautomatic Ubbelohde viscometer, the first derivative UV-spectrophotometric method and using on an X'Pert SW X-ray diffractometer (Philips), respectively.

Chitosan, C1 and C24 were employed as biopolymers for films preparation. D (+) anhydrous-glucose $(\mathrm{Glu})\left(\mathrm{C}_{6} \mathrm{H}_{12} \mathrm{O}_{6} ; 180 \mathrm{~g} \mathrm{~mol}^{-1}\right)$ was used as reducing sugars to initiate the Maillard reaction (MR) in chitosan-based films. Anydrous glycerol was purchased from Fluka (98\% purity, Fluka Chemical, Germany) and used as plasticizer for the films. All other reagents were of analytic grade.

\subsection{Films preparation}

Chitosan or CDP-based films were prepared according to the casting technique. A mother film-forming solution (FFS) was firstly prepared by dissolving the used polymer $(10 \mathrm{mg} / \mathrm{ml})$ in acetic acid $(1 \%, \mathrm{v} / \mathrm{v})$ and stirred continuously at room temperature to obtain homogeneous solution. Then, two films categories were prepared. First, chitosan or CDP-based films were obtained by adding glycerol to the FFS, at a concentration of $15 \%$ (w/w polymer), and stirring for $30 \mathrm{~min}$. Second, polymer-glucose-containing films were prepared to promote MR development. Glucose $(0.5 \mathrm{mg} / \mathrm{ml})$ was added to the FFSs containing $15 \%$ (w/w polymer) of glycerol. Subsequently, a volume of $34.0 \mathrm{ml}$ of each mixture with or without glucose was cast in Petri dishes $(13.5 \times 13.5 \mathrm{~cm})$ and left to dry for $48 \mathrm{~h}$ at $25^{\circ} \mathrm{C}$, until the total evaporation of the solvent.

After peeling, a first half of all films, referred as F1, F2 and F3 (using chitosan, C1 and C24, respectively) for films without glucose and F1-Glu, F2-Glu and F3-Glu for films containing glucose, were considered as controls. Then to favour MR, the second half of all the films was heated in an oven at $90 \pm 2{ }^{\circ} \mathrm{C}$ for $24 \mathrm{~h}$. Heated films without glucose were named F1-90, F2-90 and F3-90, while, heated films containing glucose were referred as F1-Glu-90, 
F2-Glu-90 and F3-Glu-90. All prepared films were then conditioned at $25{ }^{\circ} \mathrm{C}$ and $50 \%$ relative

124 humidity (RH) before analyses, except for FTIR, XRD, TGA and DSC measurements, films were equilibrated at $0 \% \mathrm{RH}$.

126

127

130

\subsection{Physical and structural characterization of the prepared films}

\subsubsection{Color properties and browning index}

Color of the films was performed using a CR-5 colorimeter Konica Minolta (Sensing Europe B.V) and recorded using the color parameters CIE $\mathrm{L}^{*} \mathrm{a}^{*}$ and $\mathrm{b}^{*}$. L* was expressed as lightness/brightness, $\mathrm{a}^{*}$ is a measure of greenness/redness and $\mathrm{b}^{*}$ was expressed as blueness/yellowness values. The total color changes $\left(\Delta \mathrm{E}_{1} *\right.$ and $\left.\Delta \mathrm{E}_{2} *\right)$ of the blend films were calculated according to the following equation:

$$
\Delta \mathrm{E}=\sqrt{\left(\left(\mathrm{L}^{*}-\mathrm{L}_{0}^{*}\right)^{2}+\left(\mathrm{a}^{*}-\mathrm{a}_{0}^{*}\right)^{2}+\left(\mathrm{b}^{*}-\mathrm{b}_{0}^{*}\right)^{2}\right)}
$$

where $\mathrm{L}_{0}{ }^{*}, \mathrm{a}_{0}{ }^{*}, \mathrm{~b}_{0} *$ are the colorimetric parameters of the standard $\left(\Delta \mathrm{E}_{1} *\right.$ was measured using the film $\mathrm{F} 1$ as standard, while, $\Delta \mathrm{E}_{2}{ }^{*}$ was calculated using the parameters of each control film $\mathrm{F} 1, \mathrm{~F} 2$ and $\mathrm{F} 3$ as standard in the different Mw-chitosan based films) and $\mathrm{L}^{*}, \mathrm{a}^{*}, \mathrm{~b}^{*}$ are the values of the tested films.

The obtained CIE Lab values were then used to calculate the browning index (BI) as mentionned in equation 2:

$$
\mathrm{BI}=\frac{100 \mathrm{x}(\mathrm{z}-0.31)}{0.172} \quad \text { with } \quad \mathrm{z}=\frac{\mathrm{a} *+1.75(\mathrm{~L} *)}{5.645(\mathrm{~L} *)+(\mathrm{a} *)-3.012(\mathrm{~b} *)}
$$

\subsubsection{Ultraviolet-visible barrier}

Ultraviolet-visible (UV-Vis) spectroscopy of the films was performed by using an UVvis recording spectrophotometer (Shimadzu UV-2401PC) in the wavelength range from 200 to $800 \mathrm{~nm}$. The films were cut into rectangle $(1.0 \times 3.0 \mathrm{~cm})$ and placed in the test cell of the spectrophotometer. An empty test cell was used as a reference.

\subsubsection{Water content and solubility}


To determine the moisture content (WC) of the films ( $\mathrm{g}$ moisture $/ 100 \mathrm{~g}$ film), $100 \mathrm{mg}$ of each

148 film sample were dried in an oven at $105^{\circ} \mathrm{C}$ until constant weight was reached. The weights

149 before and after drying were measured and the water content was calculated as follows:

$$
\mathrm{WC}(\%)=\frac{\left(\mathrm{m}_{\mathrm{i}}-\mathrm{m}_{\mathrm{f}}\right)}{\mathrm{m}_{\mathrm{i}}} \times 100
$$

151 where $m_{i}$ and $m_{f}$ are the initial and the final film weight $(\mathrm{g})$, respectively. Three replicates for each film were performed.

The water solubility of the films was determined according to the Gennadios, Handa,

154 Froning, Weller, \& Hanna (1998) method. Film samples $(2.0$ x $5.0 \mathrm{~cm})$ were weighted and transferred to centrifuge tube containing $30 \mathrm{ml}$ of distilled water with $0.1 \%$ (w/v) sodium azide as antimicrobial agent. The mixture was shaken at $200 \mathrm{rpm}$ speed at $25^{\circ} \mathrm{C}$ during $24 \mathrm{~h}$ and then centrifuged at $8000 \mathrm{rpm}$ at $25{ }^{\circ} \mathrm{C}$ for $10 \mathrm{~min}$. The undissolved debris were dried at $105{ }^{\circ} \mathrm{C}$ for $24 \mathrm{~h}$ to determine the remaining pieces of films. Water solubility (WS) was calculated according to the following equation:

$$
\text { WS }(\%)=\frac{\left[\left(\mathrm{m}_{\mathrm{i}} \times(100-\mathrm{WC})\right)-\mathrm{m}_{\mathrm{f}}\right]}{\left(\mathrm{m}_{\mathrm{i}} \times(100-\mathrm{WC})\right)} \times 100
$$

161 where $m_{i}$ and $m_{f}$ are the initial and final film weights $(\mathrm{g})$, respectively and $\mathrm{WC}$ is the water content of each film sample (\%).

\subsubsection{Water contact angle}

The contact angle measurements were carried out using the sessile drop method on a goniometer (Drop Shape Analyzer 30 from Kruss $\mathrm{GmbH}$ ), equipped with an image analysis software (ADVANCE). First, films were fixed in a glass plate. Then, a droplet of water $(3 \mu 1)$ was deposited on the film surface with a precision syringe. The method is based on image processing and curve fitting for contact angle measurement from a theoretical meridian drop profile, determining contact angle between the baseline of the drop and the tangent at the drop boundary. Six measurements per films were carried out. All the tests were conducted in an 
171 environmental chamber with a constant environment at a temperature of $25( \pm 2){ }^{\circ} \mathrm{C}$ and a

172 relative humidity of $50( \pm 1) \%$.

\section{$173 \quad$ 2.3.5. Films thickness}

174

175

176

177

178

180

181

182

183

184

185

186

187

188

189

190

192

193

194

The thickness of the prepared films was measured using a micrometer (Digimatic IP65, Mitutoyo, France). Six random locations around each film sample were used for average thickness determination. The mean value was considered for mechanical properties parameters calculation.

\subsubsection{Films mechanical properties}

The films mechanical properties were performed based on the determination of the tensile strength (TS, MPa) and elongation at break (EAB, \%) parameters by using a rheometer apparatus (Physica MCR, Anton Paar, GmbH, France) equipped with a mechanical property measuring geometry. Prior to analysis, all the film samples were equilibrated at $25{ }^{\circ} \mathrm{C}$ and $50 \%$ RH for a week and their thickness was measured. Then, rectangular films $(1.0 \times 4.5 \mathrm{~cm})$ were cut to get tensile test piece with an accurate width and parallel sides throughout the entire length. Based on the ISO standard, equilibrated films samples, retained in the extension grips of the measuring system, were subjected to a uniaxial tensile test, with a deformation rate of $5 \mathrm{~mm} / \mathrm{min}$ until breaking. Rheoplus software was used for the estimation of TS and EAB, corresponding respectively to the maximum load and the final extension at break from the stress-strain curves. Measurements were carried out at $25{ }^{\circ} \mathrm{C}$ and six samples for each formulation were tested.

\subsubsection{Thermal stability analysis}

The thermal stability of the film samples was carried out using a thermogravimetric analysis (TGA, Q500 High Resolution, TA Istruments). This technique allows the continuous weighting of the film sample mass in percentage $(\%)$ as a function of the temperature rise in a controlled nitrogen atmosphere. The film samples were heated from 30 to $600{ }^{\circ} \mathrm{C}$ at a heating 
rate of $20{ }^{\circ} \mathrm{C} / \mathrm{min}$. Weight loss $(\Delta \mathrm{w}, \%)$, temperature of maximum degradation $\left(\mathrm{T}_{\max },{ }^{\circ} \mathrm{C}\right)$ and

196 final residue at $600{ }^{\circ} \mathrm{C}(\%)$ values were determined using TA Universal Analysis 2000 software

197 (Version 4.5 A, TA instruments).

\subsubsection{Fourier transform infrared spectroscopy (FTIR) analysis}

The FTIR spectra of film samples were determined using a spectrometer (Agilent Technologies, Cary 630 series) equipped with an attenuated reflection accessory (ATR) containing a diamond/ZnSe crystal, at $25{ }^{\circ} \mathrm{C} .32$ scans were collected with $4 \mathrm{~cm}^{-1}$ resolution in $500-4000 \mathrm{~cm}^{-1}$ wavelength range. Prior to analysis, calibration was performed using background spectrum recorded from the clean and empty diamond. Data analysis and treatment were carried out by using the OMNIC spectra software (Thermo Fisher Scientific).

\subsubsection{X-ray diffraction (XRD) analysis}

XRD analysis of the prepared films was carried out on a Philips diffractometer using a $\mathrm{Cu} \mathrm{K} \mathrm{K}_{\alpha}$ radiation source. The samples were scanned continuously at a voltage of $40 \mathrm{kV}$ and a current of $30 \mathrm{~mA}$ with the ranging $2 \theta$ from 7 to $40^{\circ}$. Where $\theta$ is the incidence angle of the $\mathrm{X}$ ray beam on the sample.

\subsubsection{Films microstructure}

The surface and cross-section morphology of the films were assessed using a scanning electron microscopy (SEM, Hitachi S4800). The cross-section observations were performed at an angle of $90^{\circ}$ to the surface and using different magnifications. Prior to imaging, samples were cryo-fractured by immersion in liquid nitrogen, cut and fixed on the SEM support using double side adhesive tape under an accelerating voltage of $2 \mathrm{kV}$ and an absolute pressure of 60 $\mathrm{Pa}$, after sputter coating with a $5 \mathrm{~nm}$ thick gold.

\subsection{Films antioxidant potential}

\subsection{1. $\mathrm{ABTS}^{+}$radical-scavenging activity}


The $\mathrm{ABTS}^{+}$radical-scavenging capacity of the films was determined according to the method of Re et al. (1999). This test is based on the ability of antioxidant molecules to quench the long-lived $\mathrm{ABTS}^{+}$species. The $\mathrm{ABTS}^{+}$radical was generated by mixing $7 \mathrm{mM} \mathrm{ABTS}^{+}$ solution with $2.45 \mathrm{mM}$ potassium per sulphate. This solution was then diluted with ethanol to adjust the absorbance to approximately 0.7 at $734 \mathrm{~nm} .100 \mu \mathrm{l}$ of distilled water containing 10 mg film samples were added to $900 \mu \mathrm{l}$ of diluted $\mathrm{ABTS}^{+}$solution. A solution without samples was recorded as control. The mixtures were incubated at $25^{\circ} \mathrm{C}$ for $10 \mathrm{~min}$. The absorbance was then determined at $734 \mathrm{~nm}$ and $\mathrm{ABTS}^{+}$radical-scavenging capacity was computed using the following equation:

$$
\mathrm{ABTS}^{+} \text {radical scavenging activity }(\%)=\frac{\mathrm{A}_{\mathrm{C}}+\mathrm{A}_{\mathrm{B}}-\mathrm{A}_{\mathrm{R}}}{\mathrm{A}_{\mathrm{C}}} \times 100
$$

where $A_{C}$ is the absorbance of the control $\mathrm{ABTS}^{+}$solution; $\mathrm{A}_{\mathrm{R}}$ is the absorbance of film sample with $\mathrm{ABTS}^{+}$solution and $\mathrm{A}_{\mathrm{B}}$ is the absorbance of blank tubes containing sample without addition of $\mathrm{ABTS}^{+}$solution. The values are presented as the means of triplicate analyses.

\subsubsection{DPPH radical-scavenging assay}

The ability of the elaborated films to scavenge DPPH radical was determined according to Bersuder, Hole, \& Smith (1998). Firstly, the films were cut into small pieces ( $\mathrm{m}=10 \mathrm{mg}$ ) and immersed in $500 \mu 1$ of disillited water. $500 \mu 1$ of each film sample were added to $375 \mu 1$ of 99.5\% ethanol and $125 \mu \mathrm{l}$ of $0.02 \% \mathrm{DPPH}$ (in $99.5 \%$ ethanol). Then, the mixtures were incubated in the dark for $24 \mathrm{~h}$ at $25^{\circ} \mathrm{C}$. The control was conducted in the same manner, expect that distilled water was used instead of film sample. Finally, the absorbance of the solutions was mesured at $517 \mathrm{~nm}$, using a UV-visible spectrophotometer. In fact, in its radical form, DPPH has an absorption band at $517 \mathrm{~nm}$ which disappears upon reduction by antiradical compounds. DPPH radical-scavenging activity was calculated as follows: 
where $A_{C}$ is the absorbance of the control reaction, $A_{R}$ and $A_{B}$ are the absorbance of film sample

244 in the reaction mixture and without addition of DPPH solution, respectively. The assay was 245 carried out in triplicate.

\subsubsection{Reducing power assay}

The capacity of the different films to reduce iron (III) was performed according to the

method described by Yildirim, Mavi, \& Kara (2001). $500 \mu 1$ of distilled water containing 10

$249 \mathrm{mg}$ of each film were added to $1.25 \mathrm{ml}$ of $0.2 \mathrm{M}$ phosphate buffer ( $\mathrm{pH} 6.6$ ) and $1.25 \mathrm{ml}$ of $1 \%$

250 (w/v) potassium ferricyanide. After incubation at $50{ }^{\circ} \mathrm{C}$ for $3 \mathrm{~h}, 1.25 \mathrm{ml}$ of $10 \%(\mathrm{w} / \mathrm{v})$

251 trichloroacetic acid were added to the mixture which was then centrifuged. $1.25 \mathrm{ml}$ of the

252 supernatant of each sample were mixed with $1.25 \mathrm{ml}$ of distilled water and $0.25 \mathrm{ml}$ of $0.1 \%$

$253(\mathrm{w} / \mathrm{v})$ ferric chloride. After incubation at room temperature for $10 \mathrm{~min}$, the absorbance of the

254 final solutions was measured at $700 \mathrm{~nm}$. Higher absorbance of the reaction mixture showed

255 higher reducing power. The experiments were carried out in triplicate.

\subsubsection{Total antioxidant activity}

This test is based on the reduction of Mo (VI) to Mo (V) by the sample and the subsequent formation of a green phosphate/Mo (V) complex at acidic pH (Prieto, Pineda, \& Aguilar, 1999). $100 \mu \mathrm{l}$ of distilled water containing $10 \mathrm{mg}$ of film sample were homogenized with $1 \mathrm{ml}$ of 260 reagent solution $(0.6 \mathrm{M}$ sulphuric acid, $28 \mathrm{mM}$ sodium phosphate and $4 \mathrm{mM}$ ammonium 261 molybdate) and incubated at $90{ }^{\circ} \mathrm{C}$ for $90 \mathrm{~min}$. The absorbance was measured at $695 \mathrm{~nm}$ against 262 a control solution, containing $100 \mu \mathrm{l}$ distilled water instead of sample. The total antioxidant 263 activity was expressed as $\alpha$-tocopherol equivalents using the following equation:

$$
\mathrm{A}=0.011 \times \mathrm{C}+0.0049 ; \mathrm{R}^{2}=0.987
$$

where $\mathrm{A}$ is the absorbance at $695 \mathrm{~nm}$ and $\mathrm{C}$ is the concentration expressed as $\alpha$-tocopherol 266 equivalents $(\mu \mathrm{mol} / \mathrm{ml})$. 


\subsection{Statistical analysis}

Experiments were carried out in triplicate, except films water contact angle, tickness and mechanical properties analyses, which were repeated six times, and average values with standard deviation errors are reported. Statistical analyses were performed with SPSS software package ver. 17.0 professional edition (SPSS, Inc., Chicago, IL, USA) using ANOVA analysis and differences were considered significant at $p$ value $<0.05$.

\section{Results and discussion}

\subsection{Polymer characterization and films preparation}

The physicochemical characterization of chitosan $(\mathrm{Ch})$ and its high molecular weight (Mw) depolymerization products (CDP) $\mathrm{C} 1$ and $\mathrm{C} 24$ was carried out. The average Mw, the intrinsic viscosity and the crystallinity index were lower in the CDP as compared to the native chitosan Ch. However, all of them exhibited the same acetylation degree $(p>0.05)$ (Table 1).

Then, to evaluate the influence of chitosan and its derivatives ( $\mathrm{Ch}, \mathrm{C} 1$ and $\mathrm{C} 24)$, as amino

$280\left(-\mathrm{NH}_{2}\right)$ group donor on the physical, structural and antioxidant properties of CDP-based films, 281 glucose as carbonyl $(-\mathrm{C}=\mathrm{O})$ group donor was added to promote Maillard reaction $(\mathrm{MR})$.

Table 1: Physicochemical characterization of chitosan and its derivatives obtained by enzymatic hydrolysis of chitosan using the bacterial crude chitosanase from B. licheniformis 284 strain.

\begin{tabular}{ccccc}
\hline Polymer & $\begin{array}{c}\text { Molecular } \\
\text { weight (kDa) }\end{array}$ & $\begin{array}{c}\text { Intrinsic } \\
\text { viscosity (dl/g) }\end{array}$ & $\begin{array}{c}\text { Acetylation } \\
\text { degree (\%) }\end{array}$ & $\begin{array}{c}\text { Crystallinity } \\
\text { index (\%) }\end{array}$ \\
\hline Ch & 1244.70 & $7.8 \pm 0.21^{\mathrm{A}}$ & $7.60 \pm 0.54^{\mathrm{A}}$ & 74.40 \\
C1 & 482.03 & $1.81 \pm 0.02^{\mathrm{B}}$ & $8.12 \pm 0.03^{\mathrm{A}}$ & 61.89 \\
C24 & 163.56 & $1.25 \pm 0.02^{\mathrm{C}}$ & $8.83 \pm 0.33^{\mathrm{A}}$ & 51.30 \\
\hline
\end{tabular}

285 Means with different letters (A-C) and within a column indicate significant difference $(p<$ $2860.05)$. 


\subsection{Effect of MR on Films color and light barrier properties}

Among the basic properties of a film to be applied in the food packaging areas, optical features, including color, are considered a key factor affecting the appearance of coated products as well as the consumer's acceptability.

\subsubsection{Films color parameters}

The change in film's color is considered an important indicator of the occurrence and extent of MR (Kchaou et al., 2019). As shown by visual observation, the unheated films, supplemented or not with glucose, were colorless, transparent and homogenous, whereas, a narrow change to yellow was noted regarding the color of the heated glucose-free films (Fig.

S1). However, the color of the MR crosslinked films changed visually turning toward dark yellow. This variation was more pronounced in the film F3-Glu-90 followed by F2-Glu-90 and F1-Glu-90, implying that the generation of MRP was more induced for these systems probably since there was less stearic hindrance when lower Mw chitosan depolymerization products (CDP) were used (Leceta et al., 2013b).

The final stage of MR was further evaluated by color measurement using CIELab scale and $\mathrm{L}^{*}$ (whiteness/darkness), $\mathrm{a}^{*}$ (greenness/redness) and $\mathrm{b}^{*}$ (blueness/yellowness) values parameters were used to calculate total color change $\left(\Delta \mathrm{E}^{*}\right)$ and browning index $(\mathrm{BI})$ values.

Results are given in Table 2. Interestingly, $L^{*}$ values decreased significantly in the heated films containing glucose, indicating that these films turn darker. Further, this decrease was more noticeable in the films containing the lowest Mw-CDP (F3-Glu-90 and F2-Glu-90) as compared to F1-Glu-90. However, negligible change of color has been observed for free-glucose heated 308 films, showing that the thermal treatment was not the main factor affecting the films color. 309 Darker films with lowering lightness $\left(\mathrm{L}^{*}\right)$ are advantageous to prevent oxidative deterioration by coating sensitive to light foods (Yang et al., 2015). The development of the dark yellowish color is related to the production of dark products after $24 \mathrm{~h}$ of heating at $90{ }^{\circ} \mathrm{C}$ due to the 
312 interactions between chitosan/CDP and glucose through MR. Indeed, conversely to a* values

313 variations, $b^{*}$ values increased significantly in the heated films as compared to the non-heated 314 ones toward the green and yellow regions, respectively, for $\mathrm{a}^{*}$ and $\mathrm{b}^{*}$ coordinates and the most 315 significant effect was obtained with the glucose-containing heated films, especially F3-Glu-90 $316\left(a^{*}=-1.50 \pm 0.03, b^{*}=9.15 \pm 0.27\right)$. Such increase in $b^{*}$ values was related to the higher 317 reducing end content of low Mw-CDP. Results are in accordance with those of Leceta, 318 Guerrero, \& de la Caba (2013a). To better understand the above-mentioned differences between blank and MR-treated 320 films, $\Delta \mathrm{E}^{*}$ was determined. $\Delta \mathrm{E}_{1} *$ values, obtained by comparing the control films with the film 321 F1, showed a weak increase to slightly yellowish color for the films F2 and F3 due to the use 322 of low Mw-CDP. Further, the addition of glucose slightly increased the total color change in 323 all the control films. Furthermore, $\Delta \mathrm{E}_{2} *$ values were measured, taking the control films (F1, F2 and F3) as a point of reference for each Mw-chitosan-based film, in order to assess the observed differences between heated films and the non-heated ones. Results showed that $\Delta \mathrm{E}_{2} *$ increased slightly in the free-glucose heated films, but increased significantly in the heated glucose 327 containing films to $9.75,13.54$ and 14.31 for F1-Glu-90, F2-Glu-90 and F3-Glu-90, 328 respectively. This variation pointed that color change was inversely proportional to the Mw of used CDP, generating more colored films when lowest Mw-CDP were used. Similar behavior 330 of higher color change for heated lower Mw-chitosan-based films as compared to unheated ones 331 and to heated higher Mw-chitosan-based films, was reported by Leceta et al. (2013a). Such 332 results of $\Delta \mathrm{E}_{1} *$ and $\Delta \mathrm{E}_{2} *$ values indicated that MR resulted films are dark-colored and have 333 stronger barrier ability in the visible region than that of non-heated films. This color change of 334 the films conjugated with glucose could imply that the film structure also changed as a result 335 of thermal treatment during $24 \mathrm{~h}$ at $90^{\circ} \mathrm{C}$. 
337 (Matiacevich \& Pilar Buera, 2006). As shown in Table 2, low BI values were obtained in the

338 free-glucose treated films. However, similarly to the trend of $\Delta \mathrm{E}^{*}$, the BI of heated films

339 conjugated with glucose increased significantly and proportionally to the decrease of the $\mathrm{Mw}$

340 of CDP and reached $12.49 \pm 0.12,50.13 \pm 0.18$ and $71.33 \pm 3.05$ for the films F1-Glu-90, F2-

341 Glu-90 and F3-Glu-90, respectively.

342 Table 2: Color parameters $\left(\mathrm{L}^{*}, \mathrm{a}^{*}\right.$ and $\left.\mathrm{b}^{*}\right)$, total color change $\left(\Delta \mathrm{E}_{1}{ }^{*}\right.$ and $\left.\Delta \mathrm{E}_{2}{ }^{*}\right)$ and browning 343 index (BI) of the different Mw-chitosan based films with and without glucose and thermal 344 treatment.

\begin{tabular}{|c|c|c|c|c|c|c|}
\hline Films & $\mathbf{L}^{*}$ & $\mathbf{a}^{*}$ & $\mathbf{b}^{*}$ & $\Delta \mathrm{E}_{1} *$ & $\Delta \mathbf{E}_{2} *$ & BI \\
\hline F1 & $28.36 \pm 1.09^{\mathrm{A}}$ & $-0.45 \pm 0.05^{\mathrm{A}}$ & $-0.46 \pm 0.07^{\mathrm{I}}$ & - & - & - \\
\hline F1-90 & $27.30 \pm 0.85^{\mathrm{AB}}$ & $-0.60 \pm 0.03^{\mathrm{B}}$ & $0.64 \pm 0.04^{\mathrm{G}}$ & & $1.68 \pm 0.36^{\mathrm{B}}$ & $0.70 \pm 0.11^{\mathrm{E}}$ \\
\hline F1-Glu & $27.95 \pm 0.19 \mathrm{AB}$ & $-0.60 \pm 0.01^{\mathrm{B}}$ & $-0.35 \pm 0.09^{\mathrm{I}}$ & $0.47 \pm 0.15^{\mathrm{D}}$ & $0.47 \pm 0.15^{\mathrm{B}}$ & - \\
\hline F1-Glu-90 & $19.18 \pm 0.90^{\mathrm{C}}$ & $-0.67 \pm 0.04^{\mathrm{BC}}$ & $2.78 \pm 0.06^{\mathrm{C}}$ & & $9.75 \pm 0.82^{\mathrm{A}}$ & $12.49 \pm 0.12^{\mathrm{C}}$ \\
\hline F2 & $28.29 \pm 0.05^{\mathrm{A}}$ & $-0.74 \pm 0.03^{C D}$ & $0.18 \pm 0.05^{\mathrm{H}}$ & $0.71 \pm 0.02^{\mathrm{D}}$ & - & - \\
\hline F2-90 & $27.90 \pm 0.50 \mathrm{AB}$ & $-0.87 \pm 0.03^{\mathrm{E}}$ & $1.75 \pm 0.14^{\mathrm{D}}$ & & $1.70 \pm 0.01^{\mathrm{B}}$ & $3.98 \pm 0.50^{\mathrm{DE}}$ \\
\hline F2-Glu & $27.92 \pm 0.05^{\mathrm{AB}}$ & $-0.80 \pm 0.03 \mathrm{DE}$ & $0.84 \pm 0.04^{\mathrm{FG}}$ & $1.41 \pm 0.01^{\mathrm{C}}$ & $0.76 \pm 0.01^{\mathrm{C}}$ & - \\
\hline F2-Glu-90 & $16.89 \pm 0.10^{\mathrm{D}}$ & $-1.17 \pm 0.01^{\mathrm{G}}$ & $7.48 \pm 0.02^{\mathrm{B}}$ & & $13.54 \pm 0.07^{\mathrm{A}}$ & $50.13 \pm 0.18^{\mathrm{B}}$ \\
\hline F3 & $27.87 \pm 0.18^{\mathrm{AB}}$ & $-1.01 \pm 0.03^{\mathrm{F}}$ & $1.20 \pm 0.16^{\mathrm{EF}}$ & $1.83 \pm 0.09^{\mathrm{B}}$ & - & - \\
\hline F3-90 & $26.48 \pm 0.08^{\mathrm{B}}$ & $-1.19 \pm 0.03^{\mathrm{G}}$ & $2.39 \pm 0.02^{\mathrm{C}}$ & & $1.84 \pm 0.05^{\mathrm{B}}$ & $5.82 \pm 0.13^{\mathrm{D}}$ \\
\hline F3-Glu & $26.89 \pm 0.08 \mathrm{AB}$ & $-1.21 \pm 0.01^{\mathrm{G}}$ & $1.29 \pm 0.27^{\mathrm{E}}$ & $2.36 \pm 0.15^{\mathrm{A}}$ & $0.95 \pm 0.04^{\mathrm{C}}$ & - \\
\hline F3-Glu-90 & $15.99 \pm 0.05^{\mathrm{D}}$ & $-1.50 \pm 0.03^{\mathrm{H}}$ & $9.15 \pm 0.27^{\mathrm{A}}$ & & $14.31 \pm 0.1^{\mathrm{A}}$ & $71.33 \pm 3.05^{\mathrm{A}}$ \\
\hline
\end{tabular}

345 Values are means \pm standard deviation $(n=3)$. Means with different letters $(A-J)$ and within a

346 column indicate significant difference $(p<0.05) . \Delta \mathrm{E}_{1} *$ was calculated regarding to $\mathrm{F} 1$ and $\Delta \mathrm{E}_{2} *$

347 was the change of color measured as compared to each control film (F1, F2 and F3).

\section{3.2.2. Ultraviolet-visible light spectroscopy}


An effective packaging intended to food applications should demonstrate light barrier behavior to protect the packaged food from the degradative effects of light, particularly UV351 light, which generates chemical reactions catalyzation, accelerating the deterioration of food 352 and thus affecting ultimately the food quality as well as the consumer acceptance. Therefore, 353 the UV-visible spectroscopy was investigated in the range of 200-800 $\mathrm{nm}$ in order to study the 354 effect of chitosan/CDP supplementation in the extent of MR in film matrix, by analyzing their 355 light barrier properties, and to correlate color changes with the formation of MRP at different stages. As it can be seen in Fig. 1, the spectra of the different Mw chitosan-based films showed good barrier properties to light in the UV region, with a slightly better effect in the film F3, containing the lower Mw-CDP, followed by F2 as compared to F1. Further, a slight increase of the UV absorption of the heated glucose-free films (F1-90, F2-90 and F3-90) was detected, as 360 compared to the control unheated ones (F1, F2 and F3). This slight modification is probably due to the caramelization reaction caused by direct heating of carbohydrates (Li et al., 2014) and it was more pronounced in the film F3-90, followed by F2-90, as compared to F1-90. Such results were similar to those reported by Leceta et al. (2013b) who reported the same trend of

364 better barrier properties in low Mw chitosan-based films before and after treatment at $105{ }^{\circ} \mathrm{C}$, as compared to higher Mw chitosan films.

In contrast, after glucose addition, a significant change of absorbance was observed when

367 the films were heated, as compared to the unheated ones, especially when lower Mw-CDP were used. Whereas, the absorbance (A) increases noticeably, in the range of $250-450 \mathrm{~nm}$, in the 369 films F3-Glu-90 followed by F2-Glu-90 and F1-Glu-90. This obvious modification is a result 370 of MR which is a condensation reaction between nitrogen-containing compounds of chitosan 371 and its derivatives and the carbonyl group of reducing sugars (glucose) (Li et al., 2014). Such 372 reaction is a cross-linking process which follows a complex mechanism with three major stages. 373 In the initial stage, the sugar-amine conjugation allowed to the development of Amadori 
374 colorless products via rearrangement. The reaction became yellow with high UV-absorbance at

375 the intermediate stage. Whereas, brown compounds are formed in the final stage from aldol 376 condensation and aldehyde amide polymerization along with the formation of heterocyclic 377 nitrogen compounds (Gullón et al., 2016). Consequently, the color of conjugated products may 378 be a direct and easy indication of MR progress. UV-absorbance $\left(\mathrm{A}_{294 \mathrm{~nm}}\right)$ and brown color $\left(\mathrm{A}_{420}\right.$ $379 \mathrm{~nm}$ ) are typical indicators of colorless intermediate compounds and final browning compounds, 380 respectively. The changes of $\mathrm{A}_{294 \mathrm{~nm}}$ and $\mathrm{A}_{420 \mathrm{~nm}}$ of MR-crosslinked CDP-based films were 381 shown in Fig. 1. It could be found that, in all cases, the values of $\mathrm{A}_{294} \mathrm{~nm}$ were higher than those 382 obtained at $420 \mathrm{~nm}$, which is characteristic index of the formation of intermediate compounds 383 of the MR. Similarly, Kosaraju et al. (2010) stated that the thermal treatment of glucose-added 384 chitosan $(\mathrm{Mw}$ of $810 \mathrm{kDa}$ ) resulted in higher rates of intermediate browning products than final 385 browning products. Moreover, the $\mathrm{A}_{280 \mathrm{~nm}}$ and $\mathrm{A}_{420 \mathrm{~nm}}$ of the film F3-Glu-90 were higher than 386 those of the film F2-Glu-90 and especially F1-Glu-90, suggesting that MR rate was influenced 387 by the Mw of CDP-based film. This difference to induce MR regarding the Mw of 388 chitosan/CDP is due to the fact that high Mw-chitosan chains are more static, owing to its higher 389 length and compact structure, which prevent the proximity between amino and carbonyl groups 390 to react through MR (Leceta et al., 2013b). Therefore, MRP-containing films, especially F3391 Glu-90 followed by F2-Glu-90, have excellent light barrier properties, suggesting their potential 392 effect on the retardation of product oxidation induced by UV-light. These findings agreed with 393 color measurement which indicates that color change was more pronounced for lower $\mathrm{Mw}$ 394 CDP-based films. 

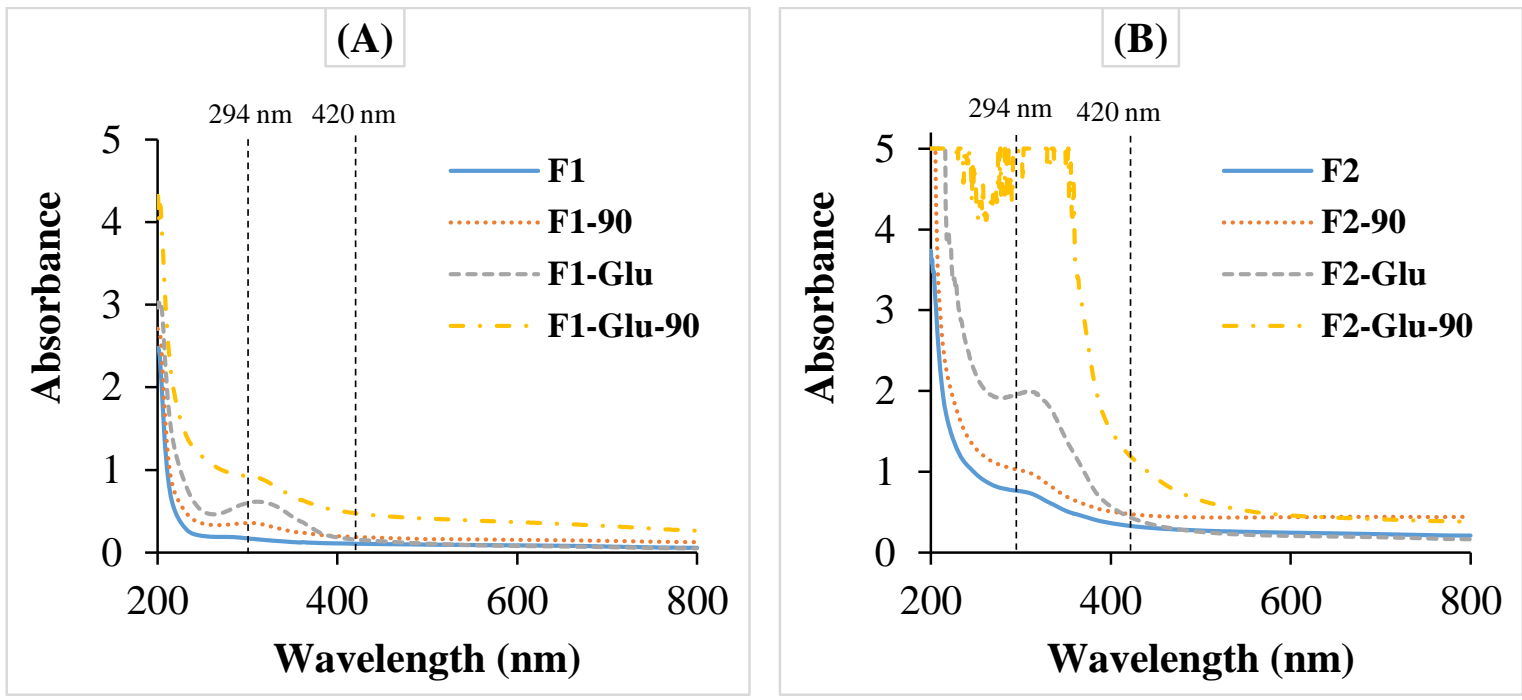

(C)

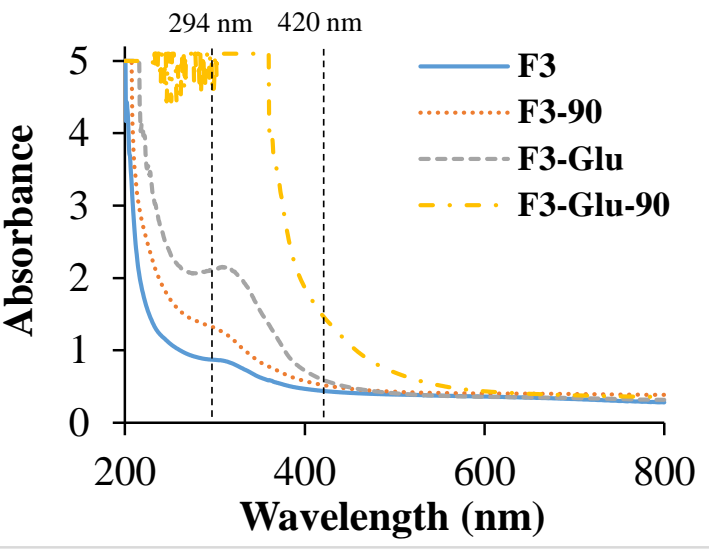

Figure 1: UV-vis spectra of chitosan (A), CDP-C1 (B) or CDP-C24 (C) based-films, with and

398 without glucose and before and after thermal treatment through MR at $90{ }^{\circ} \mathrm{C}$ during $24 \mathrm{~h}$.

\subsection{Effect of MR on films functional properties}

The functional properties of CDP-based films as influenced by MR, including water

401 content (WC), water solubility (WS) and water contact angle (WCA) were evaluated and results 402 are illustrated in Table 3 and Fig. S2.

403 Table 3: Water content (WC), water solubility (WS), water contact angle (WCA at $\mathrm{t}=10$ and

$40420 \mathrm{~s}$ ), thickness and mechanical properties (TS and EAB) of chitosan or CDP based films

405 containing or not glucose before and after thermal treatment. 


\begin{tabular}{|c|c|c|c|c|c|c|c|}
\hline \multirow{2}{*}{ Films } & \multirow{2}{*}{$\mathrm{WC}(\%)$} & \multirow{2}{*}{ WS $(\%)$} & \multicolumn{2}{|c|}{$\operatorname{WCA}\left(^{\circ}\right)$} & \multirow{2}{*}{ Thickness ( $\mu \mathrm{m})$} & \multirow{2}{*}{ EAB $(\%)$} & \multirow{2}{*}{ TS (MPa) } \\
\hline & & & $\mathbf{T}_{10 \mathrm{~s}}$ & $\mathbf{T}_{20 \mathrm{~s}}$ & & & \\
\hline F1 & $12.28 \pm 0.16^{\mathrm{BCD}}$ & $12.12 \pm 1.01^{\mathrm{E}}$ & $108.60 \pm 2.24^{\mathrm{A}}$ & $106.93 \pm 2.26^{\mathrm{A}}$ & $0.027 \pm 0.002^{\mathrm{A}}$ & $15.26 \pm 0.74 \mathrm{AB}$ & $17.99 \pm 0.25^{\mathrm{A}}$ \\
\hline F1-90 & $10.33 \pm 0.33^{\mathrm{E}}$ & $9.33 \pm 0.50^{\mathrm{F}}$ & $95.70 \pm 0.62^{\text {в }}$ & $95.10 \pm 0.94^{\text {В }}$ & $0.028 \pm 0.004^{\mathrm{A}}$ & $15.50 \pm 0.85^{\mathrm{A}}$ & $18.44 \pm 0.73^{\mathrm{A}}$ \\
\hline F1-Glu & $13.20 \pm 0.18^{\mathrm{ABC}}$ & $14.48 \pm 0.30^{\mathrm{D}}$ & $95.91 \pm 1.71^{\text {в }}$ & $94.14 \pm 1.49^{\text {В }}$ & $0.026 \pm 0.003^{\mathrm{A}}$ & $13.91 \pm 0.01 \mathrm{BC}$ & $17.57 \pm 1.22 \mathrm{AB}$ \\
\hline F1-Glu-90 & $10.91 \pm 0.21^{\mathrm{CDE}}$ & $9.54 \pm 0.71^{F}$ & $87.16 \pm 2.35^{\mathrm{C}}$ & $84.26 \pm 2.74^{\mathrm{C}}$ & $0.027 \pm 0.007^{\mathrm{A}}$ & $15.52 \pm 0.85^{\mathrm{A}}$ & $18.56 \pm 0.59^{\mathrm{A}}$ \\
\hline F2 & $12.41 \pm 0.37^{\mathrm{BCD}}$ & $17.93 \pm 0.85^{\mathrm{C}}$ & $65.66 \pm 3.37^{\mathrm{D}}$ & $61.39 \pm 2.35^{\mathrm{D}}$ & $0.025 \pm 0.002^{\mathrm{A}}$ & $12.23 \pm 0.52^{\mathrm{DE}}$ & $16.72 \pm 0.46^{\mathrm{ABC}}$ \\
\hline F2-90 & $11.08 \pm 0.58^{\mathrm{DE}}$ & $11.26 \pm 0.64^{\mathrm{EF}}$ & $61.86 \pm 1.84 \mathrm{DE}$ & $58.99 \pm 1.78^{\mathrm{DE}}$ & $0.026 \pm 0.001^{\mathrm{A}}$ & $13.31 \pm 0.27 \mathrm{CD}$ & $17.65 \pm 0.39 \mathrm{AB}$ \\
\hline F2-Glu & $13.85 \pm 0.35^{\mathrm{AB}}$ & $20.93 \pm 0.80^{\mathrm{B}}$ & $62.45 \pm 2.50 \mathrm{DE}$ & $59.54 \pm 2.56^{\mathrm{DE}}$ & $0.027 \pm 0.008^{\mathrm{A}}$ & $11.47 \pm 0.01^{\mathrm{E}}$ & $14.80 \pm 0.01 \mathrm{CD}$ \\
\hline F2-Glu-90 & $11.12 \pm 0.38^{\mathrm{DE}}$ & $10.12 \pm 0.88^{\mathrm{EF}}$ & $56.60 \pm 2.86^{\mathrm{EF}}$ & $53.46 \pm 3.43 \mathrm{EF}$ & $0.027 \pm 0.003^{\mathrm{A}}$ & $13.88 \pm 0.4^{\mathrm{BC}}$ & $15.57 \pm 0.75^{\mathrm{BCD}}$ \\
\hline F3 & $13.16 \pm 0.09^{\mathrm{CDE}}$ & $20.26 \pm 1.03^{\mathrm{B}}$ & $59.83 \pm 3.17^{\mathrm{DE}}$ & $57.62 \pm 4.01 \mathrm{DE}$ & $0.021 \pm 0.003^{\mathrm{A}}$ & $8.39 \pm 0.19^{\mathrm{G}}$ & $15.06 \pm 0.85^{\mathrm{CD}}$ \\
\hline F3-90 & $11.12 \pm 0.32^{\mathrm{DE}}$ & $15.98 \pm 0.70^{\mathrm{CD}}$ & $57.07 \pm 1.92^{\mathrm{EF}}$ & $53.43 \pm 1.74^{\mathrm{EF}}$ & $0.023 \pm 0.005^{\mathrm{A}}$ & $9.88 \pm 0.17^{\mathrm{FG}}$ & $16.43 \pm 0.45^{\mathrm{ABCD}}$ \\
\hline F3-Glu & $14.28 \pm 0.58^{\mathrm{A}}$ & $23.68 \pm 0.30^{\mathrm{A}}$ & $50.24 \pm 1.16^{\mathrm{FG}}$ & $47.76 \pm 1.19^{\mathrm{FG}}$ & $0.027 \pm 0.009^{\mathrm{A}}$ & $8.35 \pm 0.13^{\mathrm{G}}$ & $14.36 \pm 0.65^{\mathrm{D}}$ \\
\hline F3-Glu-90 & $11.29 \pm 0.46^{\mathrm{DE}}$ & $11.39 \pm 0.51^{\mathrm{EF}}$ & $45.26 \pm 1.02^{\mathrm{G}}$ & $41.50 \pm 1.18^{\mathrm{G}}$ & $0.027 \pm 0.002^{\mathrm{A}}$ & $10.71 \pm 0.42 \mathrm{EF}$ & $14.90 \pm 0.17 \mathrm{CD}$ \\
\hline
\end{tabular}

406 Values are means \pm standard deviation $(\mathrm{n}=3)$. Means with different letters $(\mathrm{A}-\mathrm{G})$ and within a

407 column indicate significant difference $(p<0.05)$.

408

409

410

411

412

413

414

415

416

417

418

419

420

421

\subsubsection{Water content measurement}

WC of the films as packaging material, which correspond to the total void volume occupied by water molecules, is an important factor affecting the shelf life of packaged food (Hazaveh, Mohammadi Nafchi, \& Abbaspour, 2015). As shown in Table 3, the WC of all unheated films increased when glucose was added, as compared to free-glucose-based films. Similarly, Kchaou et al. (2018) reported an increase of WC in the non-heated gelatin films as a result of glucose addition. Further, the WC of the films containing the lowest Mw-CDP (C24) was slightly higher than those of the films containing the high Mw-CDP (C1) and the native chitosan. Such increase in WC could be explained by the well-known hygroscopicity of saccharides. After induction of the MR (heat treatment at $90{ }^{\circ} \mathrm{C}$ ), the WC of all films decreased significantly as compared to the unheated ones. The decrease of WC of the films F1-Glu-90, F2-Glu-90 and F3-Glu-90, as compared to the glucose-based films may be explained by the interaction between the amino group of chitosan, $\mathrm{C} 1$ and $\mathrm{C} 24$, respectively, and the carbonyl group of glucose through MR. 


\subsubsection{Study of water solubility}

WS, which provides insight into the behavior of the film in an aqueous environment, is considered a crucial feature in defining the applications of biopolymeric films. Table 3 shows the WS values of prepared films. Control CDP-based films (F2 and F3) showed significant higher WS values, as compared to the chitosan-based film (F1). Such difference may be attributed to the Mw variation among chitosan and CDP samples which thereby affects their WS, being 15.09, 30.3 and 34.79\% for chitosan, C1 and C24, respectively (Affes et al., 2020b). Further, glucose addition in the control films increased significantly the WS, as compared to free-glucose films. This result was in agreement with Kchaou et al. (2018) who reported that glucose addition increased the WS of control fish gelatin films. However, when films were heat-treated at $90^{\circ} \mathrm{C}$, WS values decreased significantly $(p<0.05)$, indicating a change in their chemical structure. This decrease was more pronounced in the films containing glucose and especially in the lower Mw CDP-based films. Therefore, the cross-linking induced by heating and glucose addition through MR could be an effective method to control the WS of chitosan/CDP-based films, providing an important functional property of those films, as it was reported by other authors (Leceta et al., 2013b). Similarly, Fernández-de Castro et al. (2016) demonstrated that chitosan-oligosaccharides films showed higher WS values than chitosan films, when treated at $105{ }^{\circ} \mathrm{C}$. In the same context, they stated that the decrease of soluble matter in thermally-treated films was related to the decrease of free amino groups, as compared to unheated films. In this context, Etxabide, Urdanpilleta, Guerrero, \& de la Caba (2015) reported that lactose addition reduced significantly the solubility of fish gelatin film after heating at $105^{\circ} \mathrm{C}$.

\subsubsection{Water contact angle assessment}

The surface resistance of a film to water wetting and adhesion is an important property which is affected by its chemical composition and surface morphology (Bharathidasan, 
447 Narayanan, Sathyanaryanan, \& Sreejakumari, 2015). This property was studied by water 448 contact angle (WCA) measurement which is an indicator of the degree of 449 hydrophilicity/hydrophobicity of the film surface. The final state of a water drop informs about 450 the surface wettability.

Results illustrated in Fig. S2 and Table 3 show the variation of WCA as a function of chitosan or CDP-Mw, glucose addition and thermal treatment for the different films. Firstly, in 453 all films, as compared to $\mathrm{T}_{10 \mathrm{~s}}$, a slight decrease of WCA was obtained at $\mathrm{T}_{20 \mathrm{~s}}$ due to the evaporation of the water drop. Further, chitosan-based film (F1) showed the highest WCA values above 108.60 and $106.93^{\circ}$ at $\mathrm{T}_{10 \mathrm{~s}}$ and $\mathrm{T}_{20 \mathrm{~s}}$, respectively. These values agree with the results obtained by Leceta et al. (2013b) and de Britto \& Assis (2007) for chitosan-based films 457 (around 105 and $100^{\circ}$, respectively). Except F1-Glu-90, Chitosan-based films were considered 458 as hydrophobic as they exhibit WCA values higher than $90^{\circ}$. However, there is a significant decrease in WCA values in the films F2 and F3 containing lower Mw-CDP, as compared to F1, probably related to the higher moisture contents of these films, thus indicating more ability to absorb water and allowing to higher hydrophilicity. This result was in contradiction with that

462 of Leceta et al. (2013a) who stated that the Mw of chitosan did not affect significantly WCA 463 values. Furthermore, in all cases, WCA decreased slightly in the control films conjugated with 464 glucose. This variation is probably explained by the great affinity of free glucose, not yet involved in MR, towards water. After thermal treatment, WCA tends to decrease significantly

466 for all the films as compared to the control ones, indicating thereby that heating leads to an 467 increase of chitosan or CDP films hydrophilicity. Similarly, Leceta et al. (2013b) and Kchaou 468 et al. (2019) reported that the heat-treatment of chitosan and gelatin films, respectively, caused 469 a slight decrease in WCA values, due to changes in the conformation of molecules and to the 470 exposure of the hydrophilic groups toward the surface. 
Maintainig their integrity is very important for coating applied for food packaging, to

473 endure the distribution, treatment and storage occuring stress. In order to have information about flexibilty and stretchability of the different films, their mechanical properties, regarding tensile strenght (TS) and elongation at break (EAB), were evaluated. Firstly, results from Table 3 show that all films had similar thickness, around $0.026 \mu \mathrm{m}(p>0.05)$.

Further, as can be seen, among all film samples, the group of chitosan-based films showed the highest TS and $\operatorname{EAB}(p<0.05)$ values than CDP-based films groups, thus indicating that the decrease in $\mathrm{Mw}$ of $\mathrm{CDP}$ leads to a notably decrease in films mechanical properties. According to the literature, comparison of mechanical properties of chitosan-based films is difficult related to the variations in Mw, acetylation degree, concentration of chitosan and plasticizer, as well as film preparation and test conditions. Similarly, Leceta et al. (2013a) reported that films mechanical properties were related to chitosan physicochemical characteristic and contrarily to our results, they demonstrate that low Mw chitosan-based films exhibited lower TS but higher EAB than higher Mw chitosan films. Furthermore, the addition of glucose resulted in a decrease of both TS and EAB of the three unheated different Mwchitosan-based films. This decrease is in contradiction with results of Kchaou et al. (2018) who stated that the addition of glucose in gelatin-based films did not affect the mechanical parameters of unheated films. However, a significant increase of TS and EAB values was observed after thermal treatment of the films F1-90, F2-90 and F3-90, as compared to the freeglucose control films, and after MR in the films F1-Glu-90, F2-Glu-90 and F3-Glu-90, regarding to control glucose-containing films. The best properties were observed in the film F1-90, followed by F1-Glu-90 and F2-90 ( $p<0.05)$. Our results disagreed with those reported by of Hosseini, Razavi, \& Mousavi (2009) and Affes et al. (2020a) who suggested that the increase in the EAB of the films can be ascribed to the increased WC values. According to the literature, the improvement of mechanical properties of heated films is highly dependent on the 
distribution and density of both intermolecular and intramolecular interactions in the network created in chitosan films, thus leading to the formation of more compact structure induced by crosslinking through MR (Park et al., 1999).

\subsection{Effect of MR crosslinking on the thermal behavior of CDP-based films}

The thermal stability of chitosan-based films crosslinked or not with glucose was assessed by TGA analysis, in a temperature range of $30-600{ }^{\circ} \mathrm{C}$, in order to study the changes promoted by the effects of thermal treatment and chitosan Mw variation on the interactions between polar groups. The weight loss, temperature of maximium degradation $\left(\mathrm{T}_{\max }\right)$ and final residual mass of the films, determined from TGA thermograms (Fig. 2), are illustrated in Table 4.

DTGA curves of control chitosan or CDP-based films with and without glucose indicated three steps of transformations corresponding to the main stages of weight loss. The first stage observed from 30 to $140{ }^{\circ} \mathrm{C}$ was related to the loss of free and bound water. In this stage, the weight loss ranged from 9 to $12 \%$ with a slight higher values in the films containing glucose as compared to the free-glucose films. However, for the heated films, the weight loss values decreased slightly after $24 \mathrm{~h}$ of thermal treatment at $90{ }^{\circ} \mathrm{C}$ and ranged from 6 to $9 \%$. Such variations correlate with the results of WC (Table 2) which indicates that glucose-containing films (F1-Glu, F2-Glu and F3-Glu) possess higher WC values then the free ones and the treated films present lower WC than the non-heated ones. A second small weight loss (about 10\%) was observed at approximatly $140-240{ }^{\circ} \mathrm{C}$. It is probably related to entrapped water through hydrogen bonds and the elimination reaction of $\mathrm{NH}_{3}$, as mentioned by Martins, Cerqueira, \& Vicente (2012) or to the evaporation of glycerol, as suggested by Leceta et al. (2013b). In the case of the heated films, the weight loss in this stage decreased in the chitosan-based films (F190 and F1-Glu-90) and disappeared in the films containing low Mw-CDP (C1 and C24), thus indicating a change in the structure of films after heat treatment. 
522 chains (Martins et al., 2012). This transformation revealed the main stage of weight loss, 523 between 45 and $49 \%$ for unheated films. Higher weight loss values were obtained for heated 524 films from 51 to $57 \%$. Regarding the $\mathrm{T}_{\max }$, relative values showed that the glucose incorporation 525 does not affect the temperature of degradation of control chitosan or CDP-based films. 526 However, thermal treatment allows to a slight increase in the $\mathrm{T}_{\max }$ of the films with and without 527 glucose. The better thermal resistance in treated free-glucose films could be due to the 528 generation of new interactions between chitosan chains. Whereas, the development of MRP in 529 heated chitosan-glucose-based films may explain the increase of their thermal stability. Further, 530 chitosan-based films revealed higher $\mathrm{T}_{\max }$ values, about $300{ }^{\circ} \mathrm{C}$, as compared to those 531 containing CDP-C24 and CDP-C1, around 280 and $270{ }^{\circ} \mathrm{C}$, respectively. The residual weight 532 at $600{ }^{\circ} \mathrm{C}$ was higher when low $\mathrm{Mw}-\mathrm{CDP}$ were used and for the heated films regarding the 533 unheated ones. These results confirm that thermal treatment and MR modified the structure of 534 the films leading to a more thermally stable matrix which enhance the films functional 535 properties (Leceta et al., 2013b), as shown by the decrease of WS values.
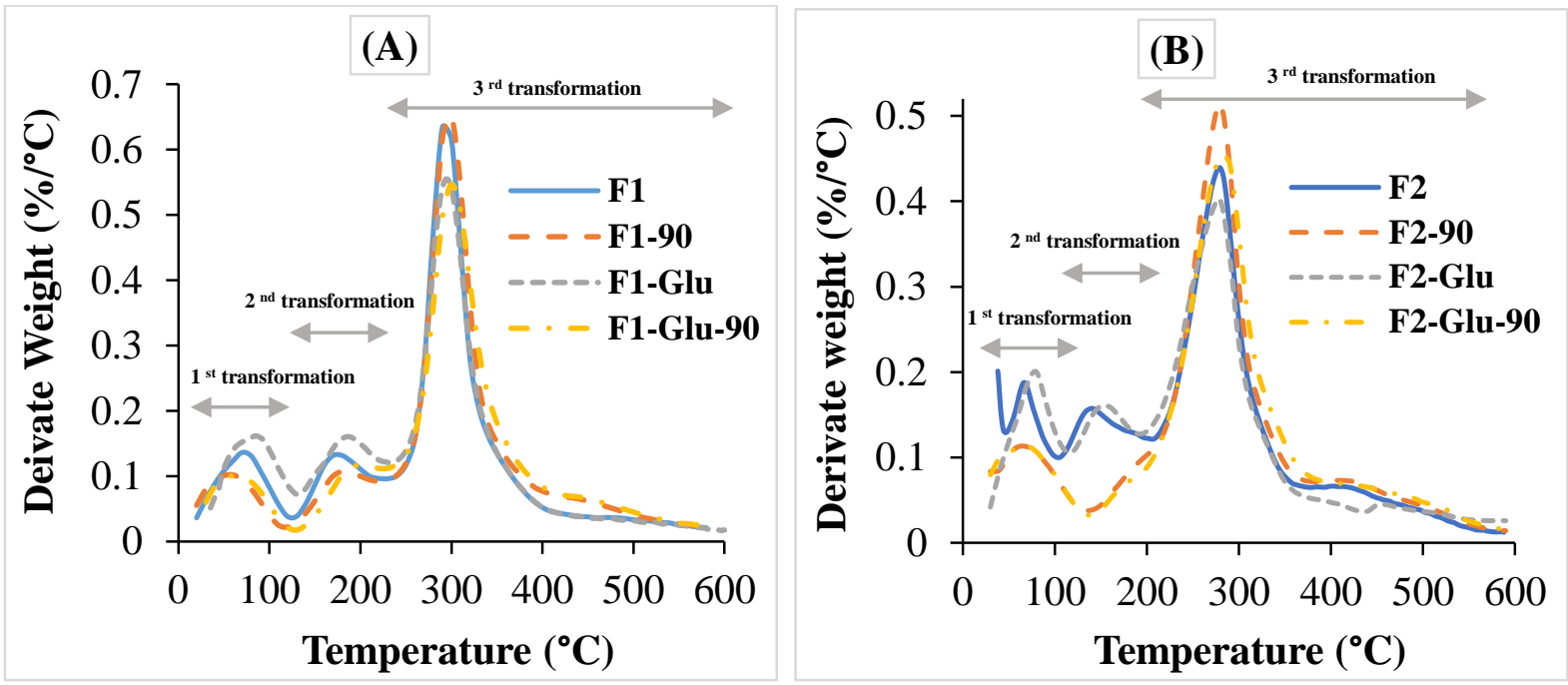


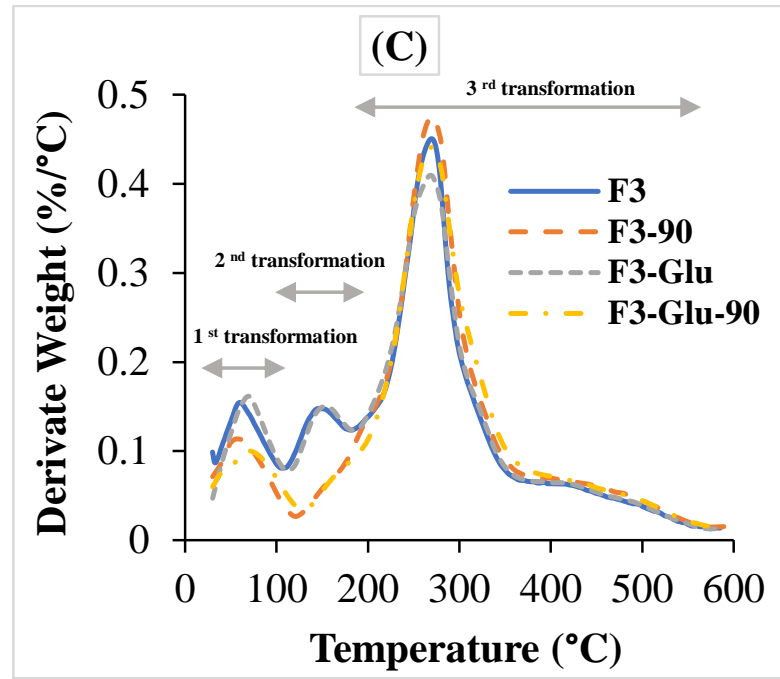

538 Figure 2: DTGA thermograms of chitosan (A) and chitosan derivatives, CDP-C1 (B) and CDP-

$539 \mathrm{C} 24(\mathbf{C})$, based films with and without glucose before and after thermal treatment at $90{ }^{\circ} \mathrm{C}$.

540 Table 4: Weight loss, maximal degradation temperature $\left(\mathrm{T}_{\max }\right)$ and residue as function of

541 degradation temperatures, based on the TGA thermograms of chitosan or CDP based films

542 conjugated or not with glucose through Maillard reaction (MR) at $90{ }^{\circ} \mathrm{C}$ as function of time $(0$ 543 and $24 \mathrm{~h})$.

\begin{tabular}{|c|c|c|c|c|c|}
\hline \multirow{2}{*}{ Films } & \multirow{2}{*}{$\begin{array}{l}\text { Temperature range for weight } \\
\text { loss at different stages }\left({ }^{\circ} \mathbf{C}\right)\end{array}$} & \multicolumn{2}{|c|}{ Weight loss (\%) } & \multirow{2}{*}{$\begin{array}{l}\text { Residual weight } \\
(\%) \text { at } 600{ }^{\circ} \mathrm{C}\end{array}$} & \multirow{2}{*}{$\mathbf{T}_{\max }\left({ }^{\circ} \mathbf{C}\right)$} \\
\hline & & Partial & Total & & \\
\hline F1 & $\begin{array}{c}30.0-135.1 \\
135.1-241.6 \\
\mathbf{2 4 1 . 6}-\mathbf{6 0 0}\end{array}$ & $\begin{array}{l}9.67 \\
10.6 \\
\mathbf{4 8 . 3}\end{array}$ & 68.57 & 31.43 & 297.00 \\
\hline F1-90 & $\begin{array}{l}30.0-131.4 \\
131.4-240 \\
\mathbf{2 4 0}-\mathbf{6 0 0 . 0}\end{array}$ & $\begin{array}{c}7.2 \\
8.8 \\
\mathbf{5 1 . 8}\end{array}$ & 67.80 & 32.20 & 298.15 \\
\hline F1-Glu & $\begin{array}{c}30.0-127.31 \\
127.31-228.59 \\
\mathbf{2 3 1 . 3}-\mathbf{6 0 0 . 0}\end{array}$ & $\begin{array}{l}11.71 \\
12.72 \\
\mathbf{4 5 . 2}\end{array}$ & 69.63 & 30.37 & 298.10 \\
\hline F1-Glu-90 & $\begin{array}{c}30.0-128.4 \\
128.4-231.3 \\
\mathbf{2 3 1 . 0}-\mathbf{6 0 0 . 0} \\
\end{array}$ & $\begin{array}{c}6.95 \\
8.5 \\
\mathbf{5 1 . 4 5} \\
\end{array}$ & 66.90 & 33.10 & 299.70 \\
\hline F2 & $\begin{array}{c}30-106.0 \\
106.0-208.3 \\
\mathbf{2 0 8 . 3}-\mathbf{6 0 0 . 0}\end{array}$ & $\begin{array}{c}10.5 \\
13.7 \\
\mathbf{4 4 . 1 7}\end{array}$ & 68.37 & 31.63 & 279.12 \\
\hline F2-90 & $30.0-139.3$ & 9.2 & 63.92 & 36.08 & 280.93 \\
\hline
\end{tabular}




\begin{tabular}{|c|c|c|c|c|c|}
\hline & $139.3-600.0$ & 54.72 & & & \\
\hline F2-Glu & $\begin{array}{c}30.0-115.7 \\
115.7-193.8 \\
\mathbf{1 9 3 . 8}-\mathbf{6 0 0 . 0}\end{array}$ & $\begin{array}{l}12.04 \\
10.88 \\
\mathbf{4 4 . 3 7}\end{array}$ & 67.29 & 32.71 & 278.10 \\
\hline F2-Glu-90 & $\begin{array}{c}30.0-128.4 \\
\mathbf{1 2 8 . 4}-\mathbf{6 0 0 . 0}\end{array}$ & $\begin{array}{c}8.6 \\
\mathbf{5 5 . 4 4}\end{array}$ & 64.04 & 35.96 & 279.12 \\
\hline F3 & $\begin{array}{c}30.0-112.1 \\
112.1-186.5 \\
\mathbf{1 8 6 . 5}-\mathbf{6 0 0 . 0}\end{array}$ & $\begin{array}{c}9.64 \\
9.3 \\
\mathbf{4 9 . 1 1}\end{array}$ & 68.05 & 31.95 & 270.88 \\
\hline F3-90 & $\begin{array}{c}30-119.3 \\
\mathbf{1 1 9 . 3}-\mathbf{6 0 0 . 0}\end{array}$ & $\begin{array}{c}7.3 \\
\mathbf{5 7 . 1}\end{array}$ & 64.40 & 35.60 & 271.25 \\
\hline F3-Glu & $\begin{array}{c}30-113.3 \\
113.3-187.7 \\
\mathbf{1 8 7 . 7}-\mathbf{6 0 0 . 0}\end{array}$ & $\begin{array}{c}9.78 \\
9.41 \\
\mathbf{4 8 . 6 8}\end{array}$ & 64.87 & 32.13 & 270.64 \\
\hline F3-Glu-90 & $\begin{array}{c}30-130.2 \\
\mathbf{1 3 0 . 2}-\mathbf{6 0 0 . 0}\end{array}$ & $\begin{array}{c}7.03 \\
\mathbf{5 6 . 4 7}\end{array}$ & 63.50 & 36.50 & 271.64 \\
\hline
\end{tabular}

544

545 3.6. Infrared spectroscopic analysis

546 Chemical bond modifications, following the establishment of interactions between

547 functional groups in chitosan or CDP-based films due to glucose addition and MR induction,

548 were studied using ATR-FTIR spectroscopy. FTIR spectra of the films at 0 and $24 \mathrm{~h}$ of heating

549 at $90{ }^{\circ} \mathrm{C}$ are given in Fig. 3. As it can be seen, all spectra revealed the same characteristic peaks.

550 A broad absorption peak was observed at $3370 \mathrm{~cm}^{-1}$ which indicates the stretching vibration of

551 the hydroxyl groups $(\mathrm{O}-\mathrm{H})$ and the intramolecular hydrogen bonding of chitosan molecules.

552 The characteristic signals of the $\mathrm{CH}$ stretching were detected at around $2875 \mathrm{~cm}^{-1}$. The peaks

553 at around 1630,1550 , and $1450 \mathrm{~cm}^{-1}$ were attributed to $\mathrm{C}=\mathrm{O}$ stretching (amide $\mathrm{I}$ ), $\mathrm{N}-\mathrm{H}$ bending

554 (amide II) and $\mathrm{C}-\mathrm{CH}_{3}$ distorting vibration, respectively. Further, glucose addition to the varying

555 Mw-chitosan/CDP-based films did not cause significant difference in the spectra in terms of

556 the location of the bands. Moreover, in the spectra of the control unheated films, the intensity

557 of the band of amide I at $1630 \mathrm{~cm}^{-1}$ was always lower than that of the band of the amide II at

$5581550 \mathrm{~cm}^{-1}$, regardless of the Mw of chitosan/CDP, as a consequence of the presence of available 
559 protonated amine groups $\left(-\mathrm{NH}_{3}{ }^{+}\right)$produced in the evaporation of solvent to form the films

560 (Fernández-de Castro et al., 2016). However, thermal treatment of the films at $90{ }^{\circ} \mathrm{C}$ reduced 561 the difference in the intensity of these two bands and the intensity of the band at $1550 \mathrm{~cm}^{-1}$ 562 become smaller, indicating the successful interaction, promoted by temperature, between 563 carbonyl and amine groups in the same chitosan chain, as well as between the carbonyl group 564 of glucose and amine group of chitosan for the films containing glucose, through crosslinking 565 and MR. This is in agreement with the decrease of WS observed for heat-treated films. Results 566 were consistent with those of Fernández-de Castro et al. (2016) and Gullón et al. (2016) in 567 which the same behavior was observed when chitosan films and chitosan polymer sample, 568 respectively, were thermally treated.
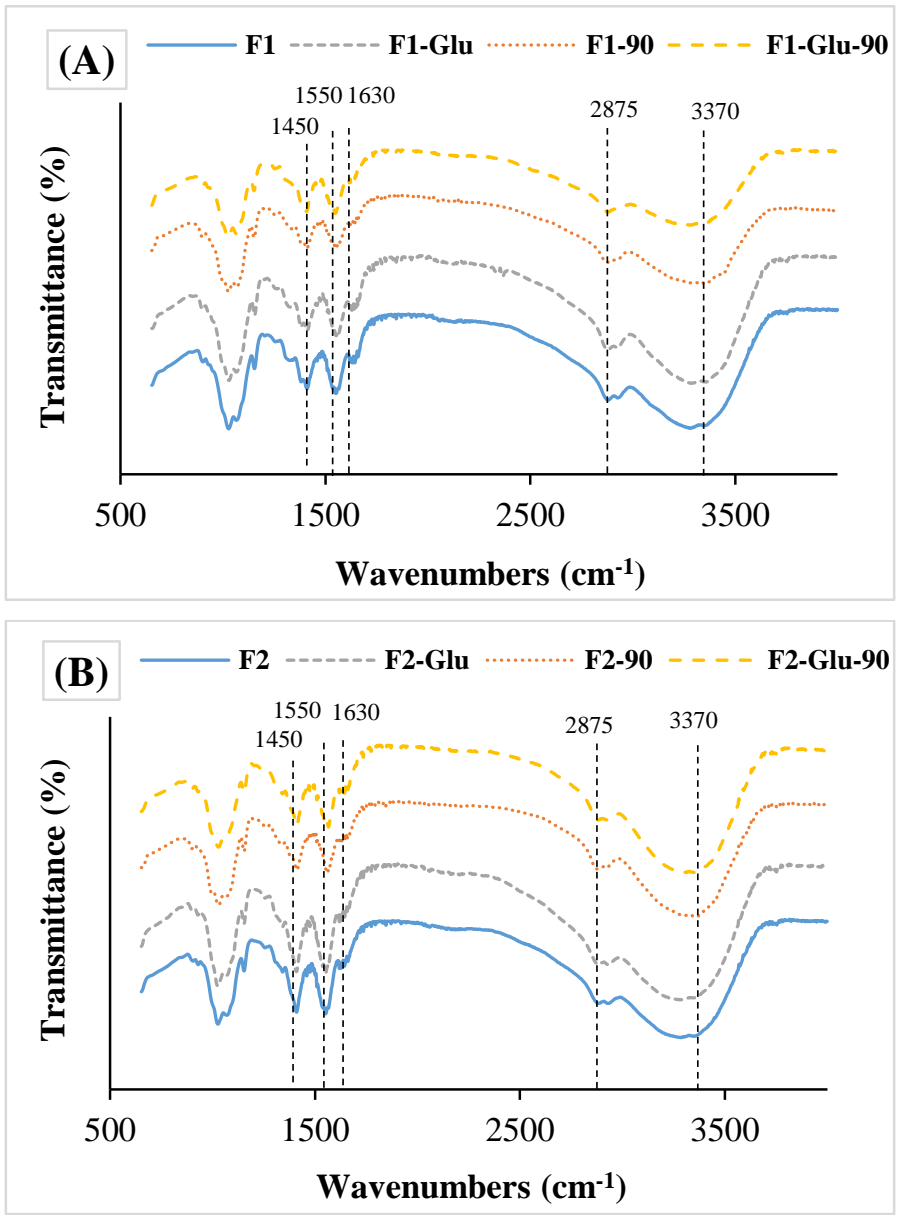


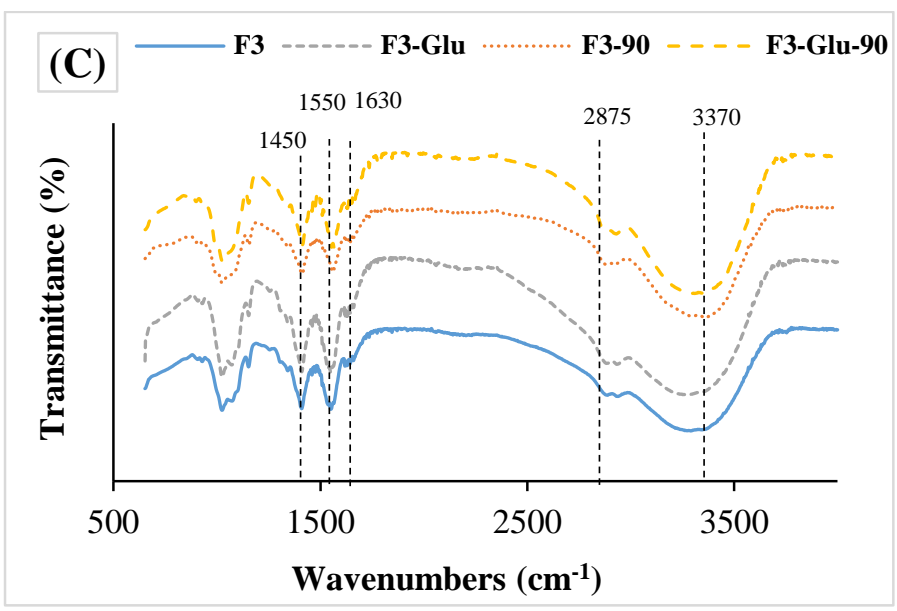

572 Figure 3: FTIR spectra of chitosan (A), CDP-C1 (B) and CDP-C24 (C) films containing or not 573 glucose, before and after heating at $90{ }^{\circ} \mathrm{C}$ during $24 \mathrm{~h}$.

\subsection{Structural properties of MR crosslinked CDP-based films}

\subsubsection{X-ray diffraction analysis}

The X-ray diffraction (XRD) analysis was assessed in order to study the crystal lattice arrangements, the structural modifications and the molecular conformation changes of the

578 prepared films caused by thermal treatment and MR. The X-ray diffractograms of chitosan and CDP-based films are shown in Fig. 4. Chitosan-based film (F1) exhibited a semi-crystalline structure with two main diffraction peaks at $2 \theta$ around 12 and $20^{\circ}$. These characteristics peaks correspond to those of chitosan sample $\left(2 \theta=10\right.$ and $20^{\circ}$ ) (Affes et al., 2020b), with a slight shift of the first peak position from $2 \theta=10$ to $12^{\circ}$, corresponding to the hydrated polymorph structure of chitosan. Similar chitosan-based films pattern was obtained by Rivero et al. (2012). The crystallinity of the CDP-based films F2 and F3 decreased, as compared to the film $\mathrm{F} 1$, showing a less intense peak at $2 \theta=20^{\circ}$, whereas, the peak at $12^{\circ}$ highly decreased in the film F2 and disappeared in the film F3. The low crystallinity of these films containing low MwCDP was attributed to the amorphous structure (Affes et al., 2020b) and low crystallinity index 588 values of CDP, as compared to native chitosan (Table1). Further, the three control unheated 589 glucose-containing films showed the same patterns as the free-glucose films. 
For heated films at $90{ }^{\circ} \mathrm{C}$, the diffractograms showed a decrease in the intensity of the

591 peak at about $20^{\circ}(2 \theta)$, as compared to the control films. Moreover, the intensity of this peak

592 was lower in the heated films containing glucose regarding to free-glucose heated films, as well

593 as in the heated films containing low Mw-CDP, as compared to those containing chitosan.

594 However, the small peak at around $12^{\circ}$ disappeared in all the thermally-treated films. Similarly,

595 Leceta et al. (2013b) and Rivero et al. (2012) reported that the first peak of chitosan film

596 disappeared by thermal treatment. From these diffractograms, it is obvious that chitosan films

597 are more crystalline than CDP films and that heated films had lower crystallinity than non-

598 heated films. The decrease of the crystallinity by thermal treatment could be related to the

599 reduction of intermolecular interactions among chitosan chains due to the formation of cross-

600 links through MR. Similarly, Leceta et al. (2013b) observed that chitosan film structure was

601 influenced by the effect of temperature.

602
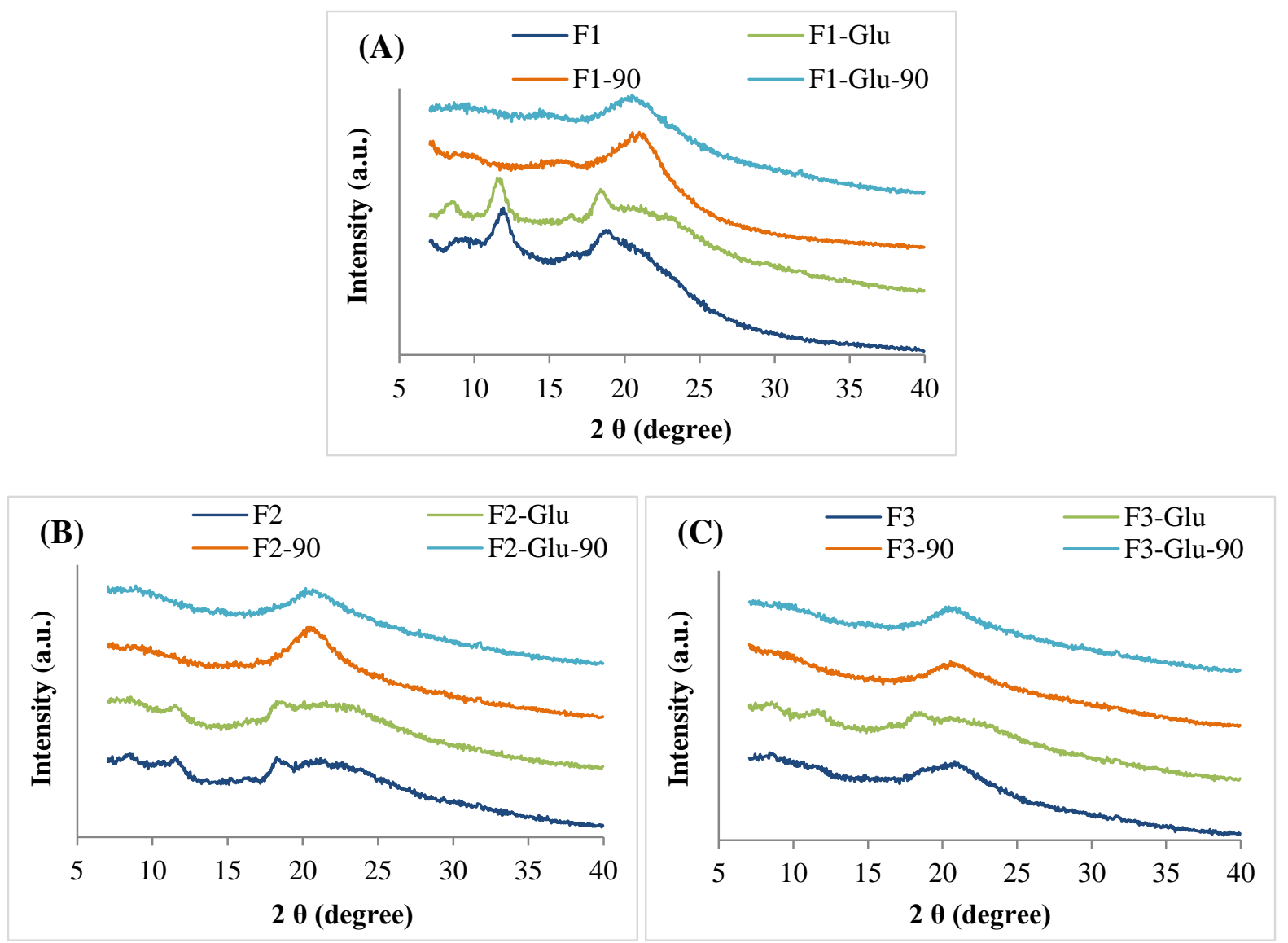
604 Figure 4: X-ray diffractograms of heat treated and non-treated chitosan (A) CDP-C1 (B) and

605 CDP-C2 (C) based films with and without glucose.

606

607

608

609

610

611

612

613

614

615

616

617

618

619

620

621

\subsubsection{Films microstructure}

Surface electron microscopy (SEM) analysis was carried out in order to assess the microstructural modifications of the elaborated films, as a function of chitosan/CDP Mw, glucose addition and cross-linking reaction, allowing a better understanding of polymers filmforming behavior. SEM micrographs illustrated in Fig. 5 showed that, in all films, the surface was flat, compact, smooth and homogenous without apparent porosity. Further, cross-sectional images of the control films with and without glucose showed a stratified structure, with an increase of the homogeneity and order of films as the Mw of chitosan-based film was higher. Similarly, Fernández-de Castro et al. (2016) reported that chitosan and chitosanoligosaccharides-based films had homogenous microstructure with relatively roughness.

However, a more compact structure was illustrated in the cross-sections of the heated films (F1Glu-90, F2-Glu-90 and F3-Glu-90), as compared to heated free-glucose films, being an indication of achievement of high interaction between chitosan and glucose due to thermal treatment, leading to the crosslinking through MR. Similarly, Etxabide et al. (2017) reported that a greater compact structure was observed for cross-sections of heated gelatin films with lactose, as compared to free-lactose films.

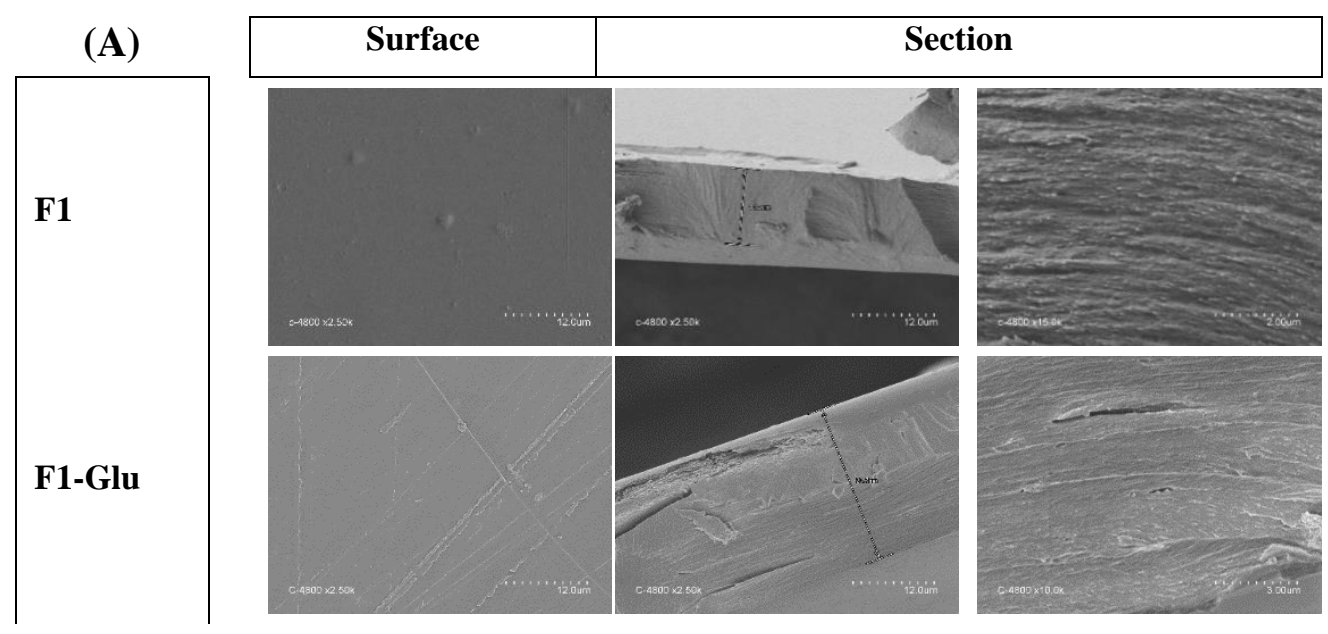



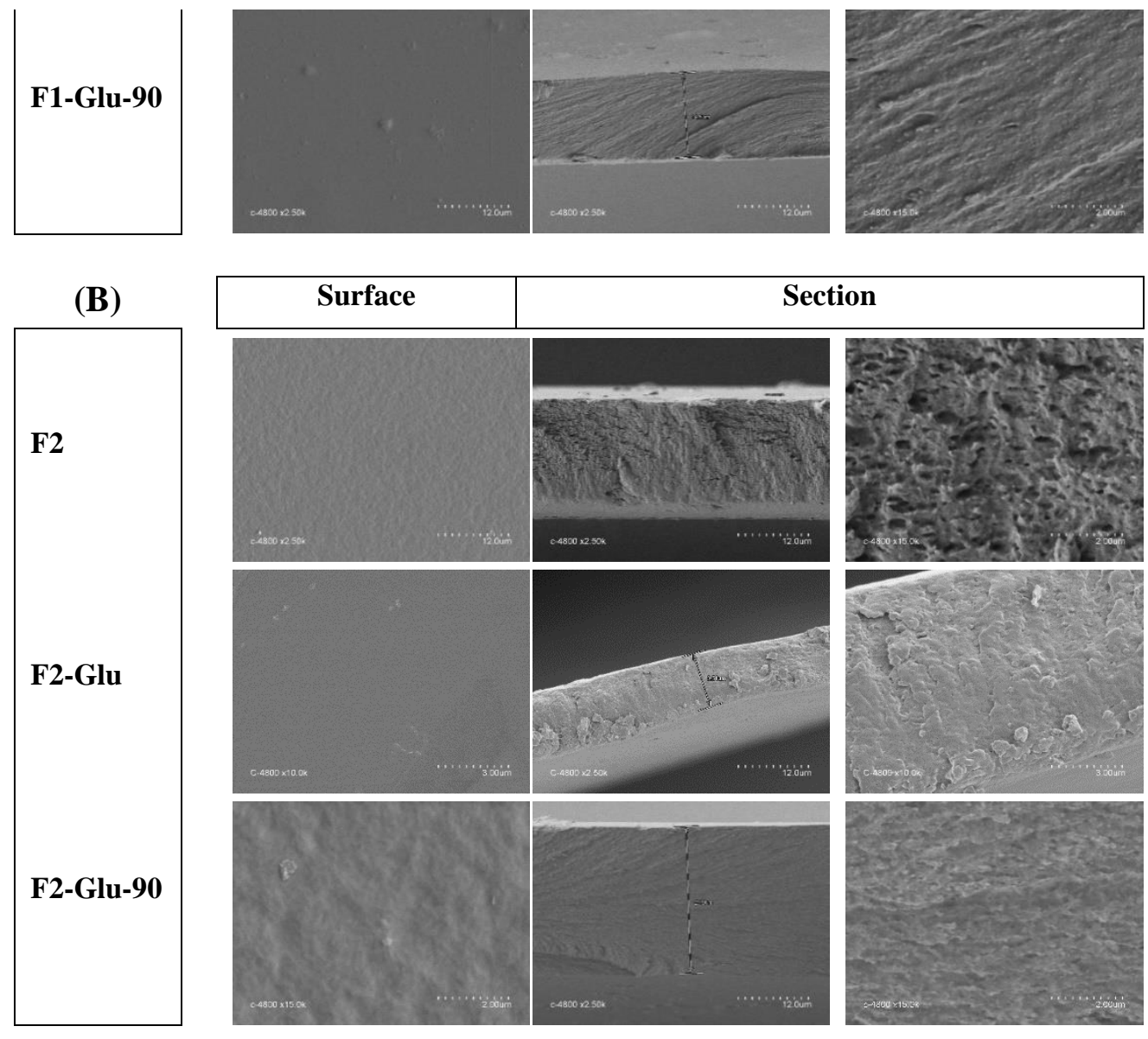

623

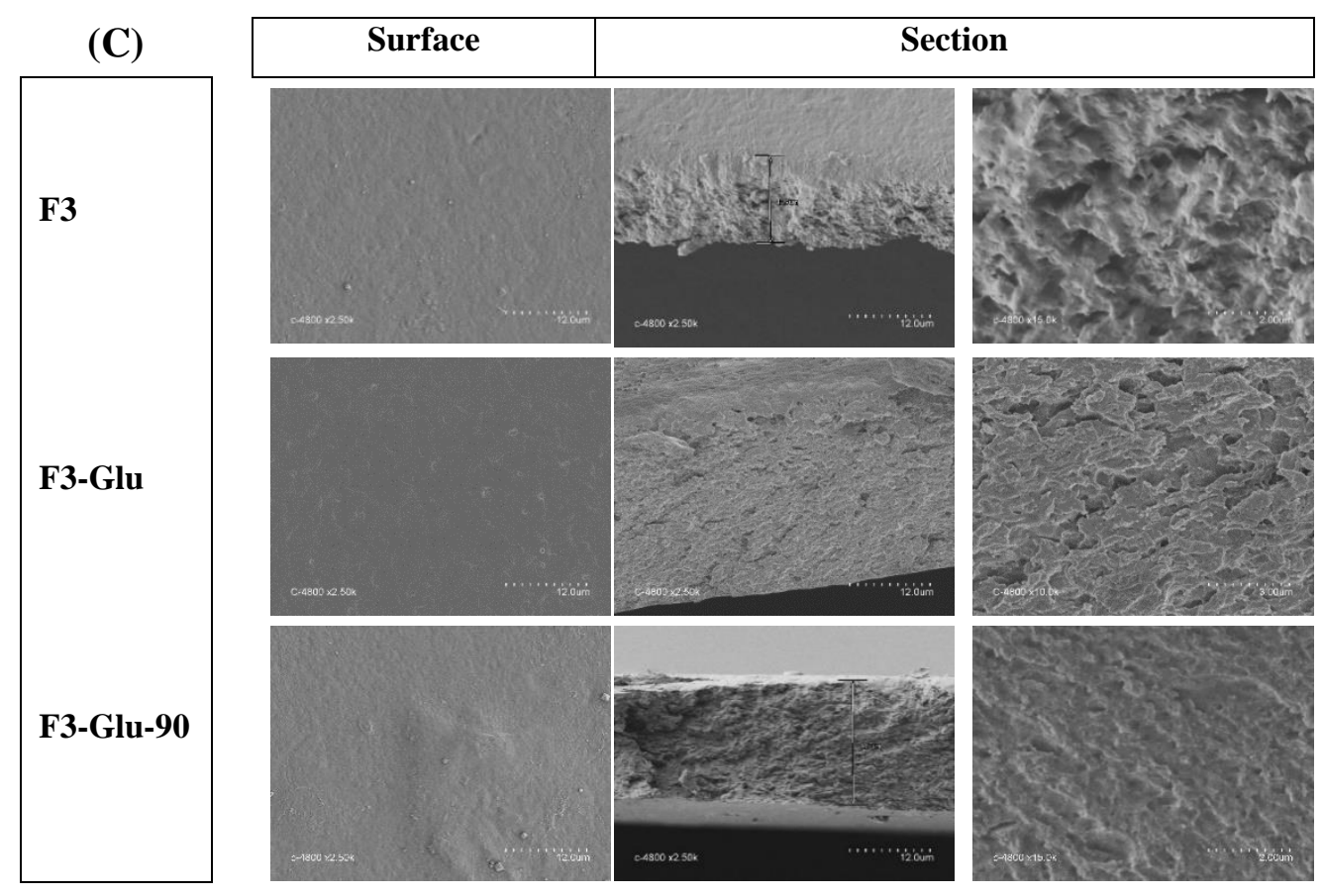

624 Figure 5: Surface and cross-section SEM micrographs of control chitosan (A), CDP-C1 (B)

625 and CDP-C2 (C) based films with and without glucose and heated films containing glucose. 
Preventing oxidative damage in foods is known as a critical function of packaging to meet the challenge of preserving the quality of food products. Accordingly, antioxidant active packaging is emerging as a promising material to satisfy the demands. With the applications of antioxidant agents in food packaging materials, oxidation reactions are significantly reduced and thereafter the shelf-life of food products is considerably prolonged.

The antioxidant potential of chitosan and CDP-based MR-treated films was investigated through different in vitro antioxidant tests, including the free radical scavenging activity, using DPPH and $\mathrm{ABTS}^{+}$radicals, the reducing power and the total antioxidant activity (Table 5). significantly $(p<0.05)$ higher in the heated-CDP-based MR crosslinked films (F1-Glu-90, F1Glu-90, F1-Glu-90) than in the blank chitosan-based film.

The $\mathrm{ABTS}^{+}$radical scavenging activity showed that, prior to heat treatment and MR induction, chitosan film (F1) exhibited the lowest potential $(56.50 \pm 0.50 \%)$ followed by F2 640 $(77.37 \pm 1.33 \%)$ and F3 $(84.55 \pm 0.39 \%)$, which is correlated to the Mw of chitosan samples 641 (the half-inhibition concentrations $\left(\mathrm{IC}_{50}\right)$ values were $1.61,0.89$ and $0.7 \mathrm{mg} / \mathrm{ml}$, respectively) 642 (Affes et al., 2020b). Additionally, when glucose was added to the control films, a slight 643 increase without significant difference was obtained. Furthermore, thermal treatment of free644 glucose films at $90{ }^{\circ} \mathrm{C}$ showed significant increase of the radical scavenging capacity. However, 645 this effect is negligible, as compared to those of the heated-glucose-containing films. 646 Interestingly, after thermal treatment of these latter films, a higher significant increase of 647 antioxidant activity especially in the films containing lower Mw-CDP $(96.04 \pm 0.81$ and 648 100.00\%, using C1 and C24, respectively) was observed. Similarly, Kchaou et al. (2019) 649 reported that ABTS radical scavenging activity of fish gelatin films conjugated with glucose 650 was significantly improved after heating at $90{ }^{\circ} \mathrm{C}$. 
652 and especially F3 exhibited higher effect (61.90 \pm 1.05 and $70.10 \pm 0.50 \%$, respectively), as compared to chitosan film (F1) $(50.92 \pm 0.31 \%)$. This variation is attributed to the enhanced

654 radical scavenging activity of chitosan-derivatives in comparison to the native chitosan, as 655 shown in our previous study ( $\mathrm{IC}_{50}$ values were about $3.07,2.78$ and $1.75 \mathrm{mg} / \mathrm{ml}$ for $\mathrm{Ch}, \mathrm{C} 1$ and 656 C24, respectively) (Affes et al., 2020b). Further, glucose addition increased slightly the DPPH 657 radical scavenging activity in three different Mw-chitosan unheated films. However, the 658 activity of the heat-treated films increased significantly in comparison with non-heated ones, 659 especially after glucose supplementation. Thus, the highest radical scavenging capacity, which 660 reached $99.65 \pm 0.35 \%$, was reached for the films containing the lowest Mw-CDP (F3-Glu-90), 661 followed by F2-Glu-90 (84.62 $\pm 1.05 \%)$ and F1-Glu-90 (99.65 $\pm 0.35 \%)$. Results demonstrate 662 that MRPs generated in the heated glucose-films increased the capacity of the films to donate 663 hydrogen atom, allowing to stabilize the free radicals. In this context, the ability of heat-induced 664 MRP to scavenge DPPH radical has been previously reported (Kchaou et al., 2019; Li et al., 665 2014; Maillard, Billaud, Chow, Ordonaud, \& Nicolas, 2007).

666 In addition, the films capacity to covert $\mathrm{Fe}^{3+}$ into $\mathrm{Fe}^{2+}$ was investigated. This test measures 667 particularly the antioxidant ability of MRPs as their hydroxyl groups play a role in the reducing 668 activity through their redox potential of transferring electrons (Vhangani \& Van Wyk, 2013). 669 Results depicted in Table 5 revealed that glucose addition enhanced the films reducing power 670 capacity even without heating and this increase is dependent on the Mw of chitosan/CDP 671 sample. Indeed, the highest optical absorbance at $700 \mathrm{~nm}$ was obtained for glucose-heated films 672 F3-Glu-90 (1.78 \pm 0.03), followed by F2-Glu-90 (1.37 \pm 0.07) and F1-Glu-90 (1.02 \pm 0.06$)$. On 673 the contrary, control unheated films showed the lowest antioxidant potential. Similarly, Li et 674 al. (2014) found that low Mw-chitosan conjugated with maltose showed higher reducing 
675 activity than high and medium Mw chitosan-maltose systems of MRP during treatment at 100 $676{ }^{\circ} \mathrm{C}$.

677 Subsequently, the total antioxidant activity of the films was further studied. Control films 678 showed the lowest antioxidant ability $(66.57 \pm 1.23,72.10 \pm 1.30$ and $87.20 \pm 0.78 \alpha$-tocopherol $679(\mu \mathrm{mol} / \mathrm{ml})$ for F1 F2 and F3, respectively). On the other hand, glucose addition resulted in a 680 slight enhancement of the films antioxidant effect, while an interesting increase was observed 681 once after thermal treatment at $90{ }^{\circ} \mathrm{C}$. Therefore, results suggest that MRPs could react with 682 Mo (VI) to convert it into more stable molecules, Mo (V) by donating electrons (Kchaou et al., 683 2018).

684 From these results, the heat treatment and especially MR development may be considered 685 as useful methods to improve the antioxidant ability of chitosan and CDP-based films, allowing 686 to conclude that glucose-containing films, especially, F3-Glu-90, could be used as an active 687 packaging in order to protect foods against oxidation.

688 Table 5: $\mathrm{ABTS}^{+}$and DPPH radicals-scavenging activities (\%), reducing power (OD $\left.700 \mathrm{~nm}\right)$ and 689 total antioxidant activity ( $\alpha$-tocopherol $(\mu \mathrm{mol} / \mathrm{ml})$ ) values of chitosan or CDP-based films 690 conjugated or not with glucose and before and after thermal treatment at $90{ }^{\circ} \mathrm{C}$.

\begin{tabular}{lcccc}
\hline Antioxidant & $\begin{array}{c}\text { ABTS radical } \\
\text { scavenging activity }(\%)\end{array}$ & $\begin{array}{c}\text { DPPH radical } \\
\text { scavenging activity }(\%)\end{array}$ & $\begin{array}{c}\text { Reducing power } \\
(\mathbf{O D} 700 \mathbf{~ n m})\end{array}$ & $\begin{array}{c}\text { Total antioxidant activity } \\
(\boldsymbol{\alpha} \text {-tocopherol }(\boldsymbol{\mu m o l} / \mathbf{m l}))\end{array}$ \\
\hline F1 & $56.50 \pm 0.50^{\mathrm{H}}$ & $50.92 \pm 0.31^{\mathrm{H}}$ & $0.22 \pm 0.01^{\mathrm{H}}$ & $66.57 \pm 1.23^{\mathrm{I}}$ \\
F1-90 & $61.00 \pm 1.65^{\mathrm{G}}$ & $58.41 \pm 0.50^{\mathrm{G}}$ & $0.62 \pm 0.01^{\mathrm{DE}}$ & $73.77 \pm 0.54^{\mathrm{GH}}$ \\
F1-Glu & $57.12 \pm 0.84^{\mathrm{H}}$ & $53.12 \pm 0.03^{\mathrm{H}}$ & $0.48 \pm 0.02^{\mathrm{FG}}$ & $72.27 \pm 067^{\mathrm{H}}$ \\
F1-Glu-90 & $70.76 \pm 0.88^{\mathrm{F}}$ & $68.59 \pm 1.24^{\mathrm{E}}$ & $1.02 \pm 0.06^{\mathrm{C}}$ & $97.21 \pm 1.01^{\mathrm{C}}$ \\
\hline F2 & $77.37 \pm 1.33^{\mathrm{E}}$ & $61.90 \pm 1.05^{\mathrm{F}}$ & $0.37 \pm 0.03^{\mathrm{G}}$ & $72.10 \pm 1.30^{\mathrm{H}}$ \\
F2-90 & $83.69 \pm 0.65^{\mathrm{D}}$ & $70.35 \pm 0.70^{\mathrm{E}}$ & $0.72 \pm 0.01^{\mathrm{D}}$ & $80.51 \pm 2.12^{\mathrm{F}}$ \\
F2-Glu & $79.54 \pm 1.03^{\mathrm{E}}$ & $64.22 \pm 0.81^{\mathrm{F}}$ & $0.55 \pm 0.05^{\mathrm{EF}}$ & $76.47 \pm 1.45^{\mathrm{G}}$ \\
F2-Glu-90 & $96.04 \pm 0.81^{\mathrm{B}}$ & $84.62 \pm 1.05^{\mathrm{B}}$ & $1.37 \pm 0.07^{\mathrm{B}}$ & $122.18 \pm 0.48^{\mathrm{B}}$ \\
\hline F3 & $84.55 \pm 0.39^{\mathrm{D}}$ & $70.10 \pm 0.50^{\mathrm{E}}$ & $0.57 \pm 0.02^{\mathrm{EF}}$ & $87.20 \pm 0.78^{\mathrm{E}}$ \\
F3-90 & $92.35 \pm 0.84^{\mathrm{C}}$ & $81.34 \pm 73.80^{\mathrm{C}}$ & $0.92 \pm 0.01^{\mathrm{C}}$ & $95.50 \pm 0.56^{\mathrm{CD}}$
\end{tabular}




$\begin{array}{lcccc}\text { F3-Glu } & 85.82 \pm 0.61^{\mathrm{D}} & 73.80 \pm 0.81^{\mathrm{D}} & 0.71 \pm 0.05^{\mathrm{D}} & 92.24 \pm 0.79^{\mathrm{D}} \\ \text { F3-Glu-90 } & 100.00 \pm 0.00^{\mathrm{A}} & 99.65 \pm 0.35^{\mathrm{A}} & 1.78 \pm 0.03^{\mathrm{A}} & 147.40 \pm 0.91^{\mathrm{A}}\end{array}$

691 Values are means \pm standard deviation $(n=3)$. Means with different letters (A-I) and within a

692 column indicate significant difference $(p<0.05)$.

\section{4. Conclusion}

694 In this study, different Mw chitosan or chitosan depolymerisation products (CDP)-based 695 films, conjugated or not with glucose, were prepared and thermally treated at $90{ }^{\circ} \mathrm{C}$ during 24

696 h. Films physicochemical properties were enhanced by crosslinking through heat treatment, as 697 compared to unheated films, especially in the films containing glucose due to Maillard reaction 698 (MR) development. Meanwhile, the most efficient rate of MR was obtained by lower Mw-CDP 699 films as confirmed by higher color changes from transparent to brown and better light barrier 700 properties. However, water resistance properties, thermal stability and mechanical behavior 701 were found to be better in higher Mw chitosan based films. Furthermore, antioxidant potential 702 of heated films assessed by four different mechanisms proved that low Mw-CDP based films 703 and more precisely, crosslinked films through MR, showed strong antioxidant activities due to 704 the reinforcement of more fonctional active groups. The obtained results promote to control the 705 extension of crosslinking in order to select the appropriate conditions for each specific 706 application. It can be concluded that MR development is a viable method that leads to generate 707 bioactive compounds, which confer better fonctional and biological properties to chitosan and 708 CDP-based films to be satisfactory for food applications, as potential packaging that ensure 709 food safety and extend the shelf-life of packaged food.

\section{Credit authorship contribution statement}

711 Sawsan Affes: Conceptualization, Methodology, Validation, Formal analysis, Investigation, 712 Writing - Original Draft. 
713 Hana Maalej: Supervision, Conceptualization, Resources, Writing - Review \& Editing.

714 Suming Li: Project administration, Investigation.

715 Rim Nasri: Project administration, Investigation.

716 Moncef Nasri: Supervision, Resources, Visualisation, Writing - Review \& Editing.

717

718

719

720

721

722

723

724

725

726

727

728

729

730

731

732 Affes, S., Maalej, H., Aranaz, I., Acosta, N., Heras, Á., \& Nasri, M. (2020b). Enzymatic 733

\section{$\underline{\text { Acknowledgements }}$}

The "Ministry of Higher Education and Scientific Research", Tunisia, funded this work. The authors gratfully acknowledge financial support provided from the framework of PHCUtique program financed by CMCU project, grant $\mathrm{N}^{\circ}: 19 \mathrm{G} 0815$.

\section{Declaration of Competing Interest}

The authors declare that there are no conflicts of interest.

\section{$\underline{\text { References }}$}

Affes, S., Aranaz, I., Hamdi, M., Acosta, N., Ghorbel-Bellaaj, O., Heras, Á., Nasri, M., \& Maalej, H. (2019). Preparation of a crude chitosanase from blue crab viscera as well as its application in the production of biologically active chito-oligosaccharides from shrimp shells chitosan. International Journal of Biological Macromolecules, 139, 558 1-569.

Affes, S., Maalej, H., Aranaz, I., Acosta, N., Kchaou, H., Heras, Á., \& Nasri, M. (2020a). Controlled size green synthesis of bioactive silver nanoparticles assisted by chitosan and its derivatives and their application in biofilm preparation. Carbohydrate Polymers, 236, 116063. production of low- $M w$ chitosan-derivatives: Characterization and biological activities evaluation. International Journal of Biological Macromolecules, 144, 279-288. 
Aljbour, N. D., Beg, M. D. H., \& Gimbun, J. (2019). Acid hydrolysis of chitosan to oligomers using hydrochloric acid. Chemical Engineering \& Technology, 42, 1741-1746.

Bersuder, P., Hole, M., \& Smith, G. (1998). Antioxidants from a heated histidine-glucose model

Bharathidasan, T., Narayanan, T. N., Sathyanaryanan, S., \& Sreejakumari, S. S. (2015). Above $170^{\circ}$ water contact angle and oleophobicity of fluorinated graphene oxide based transparent polymeric films. Carbon, 84, 207-213.

De Britto, D., \& Assis, O.B.G. (2007). A novel method for obtaining a quaternary salt of chitosan. Carbohydrate Polymers, 69, 305-310.

Etxabide, A., Urdanpilleta, M., Gómez-Arriaran, I., de la Caba, K., \& Guerrero, P. (2017). Effect of $\mathrm{pH}$ and lactose on cross-linking extension and structure of fish gelatin films. Reactive and Functional Polymers, 117, 140-146.

Etxabide, A., Urdanpilleta, M., Guerrero, P., \& de la Caba., K. (2015). Effects of cross-linking in nanostructure and physicochemical properties of fish gelatins for bio-application. Reactive and Functional Polymers, 94, 55-62.

Fernández-de Castro, L., Mengíbar, M., Sánchez, A., Arroyo, L., Villarán, M. C., de Apodaca, Technology, 73, 368-374.

756 Gennadios, A., Handa, A., Froning, G. W., Weller, C. L., \& Hanna, M. A. (1998). Physical properties of egg white-dialdehyde starch films. Journal of Agricultural and Food Chemistry, 46, 1297-1302. 
Gullón, B., Montenegro, M. I., Ruiz-Matute, A. I., Cardelle-Cobas, A., Corzo, N., \& Pintado, M. E. (2016). Synthesis, optimization and structural characterization of a chitosan-glucose derivative obtained by the Maillard reaction. Carbohydrate Polymers, 137, 382-389.

Hajji, S., Younes, I., Affes, S., Boufi, S., \& Nasri, M. (2018). Optimization of the formulation of chitosan edible coatings supplemented with carotenoproteins and their use for extending strawberries postharvest life. Food Hydrocolloids, 83, 375-392.

Hazaveh, P., Mohammadi Nafchi, A., \& Abbaspour, H. (2015). The effects of sugars on moisture sorption isotherm and functional properties of cold water fish gelatin films. International Journal of Biological Macromolecules, 79, 370-376.

Hosseini, M. H., Razavi, S. H., \& Mousavi, M. A. (2009). Antimicrobial, physical and mechanical properties of chitosan-based films incorporated with thyme, clove and cinnamon essential oils. Journal of Food Processing and Preservation, 33, 727-743.

Kchaou, H., Benbettaieb, N., Jridi, M., Nasri, M., \& Debeaufort, F. (2019). Influence of Maillard reaction and temperature on fonctional, structure and bioactive properties of fish gelatin films. Food Hydrocolloids, 97, 105196.

Kchaou, H., Benbettaïeb, N., Jridi, M., Abdelhedi, O., Karbowiak, T., Brachais, C. H., Léonard, M. L., Debeaufort, F., \& Nasri, M. (2018). Enhancement of structural, functional and antioxidant properties of fish gelatin films using Maillard reactions. Food Hydrocolloids, $83,326-339$.

Kosaraju, S. L., Weerakkody, R., \& Augustin, M. A. (2010). Chitosan-glucose conjugates: Influence of extent of Maillard reaction on antioxidant properties. Journal of Agricultural and Food Chemisrty, 58, 12449-12455.

Leceta, I., Guerrero, P., \& de la Caba, K. (2013a). Functional properties of chitosan-based films. Carbohydrate Polymers, 93, 339-346. 
Leceta, I., Guerrero, P., Ibarburu, I., Dueñas, M. T., \& de la Caba, K. (2013b). Characterization and antimicrobial analysis of chitosan-based films. Journal of Food Engineering, 116, 889-899.

Li, S. L., Lin, J., \& Chen, X.M. (2014). Effect of chitosan molecular weight on the functional properties of chitosan-maltose Maillard reaction products and their application to freshcut Typha latifolia L. Carbohydrate Polymers, 102, 682-690.

Martins, J. T., Cerqueira, M. A., \& Vicente, A. A. (2012). Influence of $\alpha$-tocopherol on physicochemical properties of chitosan-based films. Food Hydrocolloids, 27, 220-227.

Matiacevich. S. B., \& Pilar Buera. M. (2006). A critical evaluation of fluorescence as a potential marker for the Maillard reaction. Food Chemistry, 95, 423-430.

Maillard, M. N., Billaud, C., Chow, Y. N., Ordonaud, C., \& Nicolas, J. (2007). Free radical scavenging, inhibition of polyphenoloxidase activity and copper chelating properties of model Maillard systems. LWT-Food Science and Technology, 40, 1434-1444.

Park, H. J., Jung, S. T., Song, J. J., Kang, S. G., Vergano, P. J., \& Testin, R. F. (1999). Mechanical and barrier properties of chitosan-based biopolymer film. Chitin and Chitosan Research, 5, 19-26.

Prieto, P., Pineda, M., \& Aguilar, M., (1999). Spectrophotometric quantitation of antioxidant capacity through the formation of a phosphomolybdenum complex: Specific application to the determination of Vitamin E. Analytical Biochemistry, 269, 337-341.

Re, R., Pellegrini, N., Proteggente, A., Pannala, A., Yang, M., \& Rice-Evans, C. (1999). Antioxidant activity applying an improved ABTS radical cation decolorization assay. Free Radical Biology \& Medicine, 26, 1231-1237. 
805 Rivero, S., Garía, M. A, \& Pinotti, A. (2012). Heat treatment to modify the structural and 806 physical properties of chitosan-based films. Journal of Agricultural and Food Chemistry, 60, 492-499.

808

809

810

811

813

814

815

816

Ruban, S.W. (2009). Biobased packaging-application in meat industry. Veterinary Word, 2, 7982.

Sun, T., Qin, Y., Xu, H., Xie, J., Hu, D., Xue, B., \& Hua, X. (2017). Antibacterial activities and preservative effect of chitosan oligosaccharide Maillard reaction products on Penaeus vannamei. International Journal of Biological Macromolecules, 105, 764-768.

Vhangani, L. N., \& Van Wyk, J. (2013). Antioxidant activity of Maillard reaction products (MRPs) derived from fructose-lysine and ribose-lysine model systems. Food Chemistry, 137, 92-98.

Yang, H., Li, J. G., Wu, N. F., Fan, M. M., Shen, X. L., Chen, M. T., Jiang, A. M., \& Lai, L. S. (2015). Effect of hsian-tsao gum (HG) content upon rheological properties of filmforming solutions (FFS) and physical properties of soy protein/hsian-tsao gum films. Food Hydrocolloids, 50, 211-218.

Yildirim, A., Mavi, A., \& Kara, A.A. (2001). Determination of antioxidant and antimicrobial activities of Rumex crispus L. extracts. Journal of Agricultural and Food Chemistry, 49, 4083-4089.

\section{Supplementary data}


828 Figure S1: Color change of chitosan and CDP based films with and without glucose (5\%)

829 addition and before and after heating process during $24 \mathrm{~h}$ at $90{ }^{\circ} \mathrm{C}$.

830

831

832

833

834

835

836

837

838

839

840

841

842 
